TITLE:

\title{
Estimation of Production Capacity Loss Rate after the Great East Japan Earthquake and Tsunami in 2011
}

$\operatorname{AUTHOR}(S):$

Kajitani, Yoshio; Tatano, Hirokazu

\section{CITATION:}

Kajitani, Yoshio ... [et al]. Estimation of Production Capacity Loss Rate after the Great East Japan Earthquake and Tsunami in 2011. Economic Systems Research 2014, 26(1): 13-38

\section{ISSUE DATE:}

2014

URL:

http://hdl.handle.net/2433/240966

\section{RIGHT:}

This is an Accepted Manuscript of an article published by Taylor \& Francis in Economic Systems Research on 9 January 2014, available online: http://www.tandfonline.com/10.1080/09535314.2013.872081.; この論文は出版社版でありません 。引用の際には出版社版をご確認ご利用ください。; This is not the published version. Please cite only the published version. 


\title{
Estimation of Production Capacity Loss Rate after the Great East Japan Earthquake and Tsunami in 2011
}

\author{
YOSHIO KAJITANI ${ }^{*}$ and HIROKAZU TATANO ${ }^{\mathrm{b}}$
}

\begin{abstract}
${ }^{a}$ Research Scientist, Civil Engineering Laboratory, Central Research Institute of Electric Power Industry, 1646 Abiko, Abiko City, Chiba, 2701194, Japan

bProfessor, Disaster Prevention Research Institute, Kyoto University, Gokasyo, Uji City, Kyoto, 6110011, Japan
\end{abstract}

\begin{abstract}
This research aims to investigate a method for estimating the production capacity loss rate (PCLR) of industrial sectors damaged by a disaster, such as an earthquake, tsunami, or nuclear radiation, especially in the case of the 2011 Great East Japan Earthquake. PCLR is fundamental information required to gain an understanding of economic losses caused by a disaster. In particular, this paper proposes a method of PCLR estimation that considers the two main causes of capacity losses as observed from past earthquake disaster, namely damage to production facilities and disruption of lifeline systems. To achieve the quantitative estimation of PCLR, functional fragility curves considering the relationship between production capacity and earthquake ground motion and lifeline resilience factors for capturing the impact of lifeline disruptions have been adopted, while actual recovery curves are considered mainly for damaged facilities. Through the application of this method to the case study of the Great East Japan Earthquake, PCLR in various industrial sectors is estimated; the estimated PCLR in the manufacturing sectors are then compared with the corresponding index of industrial production. The results demonstrate that the estimated values are close to the actual production indices in the overall manufacturing sector and many of the This is an Accepted Manuscript of an article published by Taylor \& Francis in Economic Systems Research on 09 Jan 2014, available online: https://www.tandfonline.com/doi/full/10.1080/09535314.2013.872081.
\end{abstract}


individual sectors.

Key Words: Great East Japan Earthquake, Production Capacity, Economic Impact, Industries

\section{INTRODUCTION}

The Great East Japan Earthquake, which occurred on March 11, 2011, was one of the largest disasters ever recorded anywhere in the world and caused short- and long-term effects inside and outside the areas that suffered the direct damages. Both population losses and economic losses have been enormous, a consequence of the complex sources of damage, including the damage to buildings and infrastructure, and the disruption to lifelines and supply chains among industries (e.g. Kajitani et al., 2013a). In order to effectively reduce the losses induced by large-scale disasters in the future, it is vital to study in detail the economic losses, including the structure of complex damage propagation, which were induced by the Great East Japan Earthquake, and to reflect upon them. This will contribute to the development of a model for the estimation of economic loss induced by the similar types of disasters around the world. The local conditions, such as the building structure, magnitude of the hazard, and economic development will depend on region-specific attributes, but the analytical framework and the data accumulation strategy can be generalized for other disasters.

A production capacity loss rate (hereinafter referred to as "PCLR") in an industrial sector is one of the most important sources of information for understanding the scale of any economic impact, especially in the dimension of outputs. In principle, production capacity mainly refers to production ability on the supply side and PCLR is a standardized production capacity loss where the production capacity before the disaster is set as 1. In the Great East Japan Earthquake, production decrease in the wider regions was induced by shortages of goods to meet intermediate demand as well as intermediate demand decrease due to the production capacity loss.

In terms of the assessment of economic impact caused by disasters, conventional approaches based on the input-output (I-O) table are often applied to the assessment of economic impacts with the restriction of production capacity (i.e., PCLR is identified) in the physically damaged 
areas. For example, in the case of the Great East Japan Earthquake, MacKenzie et al. (2012) decomposed the production index in Japan using a multi-country I-O model and derived the proportion of direct and indirect impacts ${ }^{1}$ reflected in production index in Japan. Their postdisaster analysis indicates that direct impact is approximately $40 \%$ of total production losses.

However, there has been a limited number of studies conducted on PCLR estimation model, which produces information indispensable for estimating output losses in a proactive manner. In most of the economic loss assessment studies based on the conventional approaches, such as I-O modeling, PCLR tends to be determined in an ad hoc manner or ignored, and it is not likely that scenario hazard, business vulnerability, and resilience information is fully utilized for such settings. There are some estimates for PCLR, which target specific conditions such as lifeline disruptions and facility damages, but the performance of these research outputs has to be demonstrated in the context of an empirical case.

In consideration of this background, this paper aims to propose a model for PCLR estimation and to demonstrate the model performance through its application to the Great East Japan Earthquake. Specifically, this model elaborates on multiple hazards (i.e., earthquake ground motion, tsunami and nuclear accident) and the inter-related vulnerabilities of businesses in the face of such hazards. Business resilience is considered to illustrate the remaining production level associated with recovery during the disaster. Vulnerability and resilience assessment are implemented based on previous post-disaster business surveys.

The capacity loss estimation model developed in this paper is applied to those regions severely damaged in the Tohoku region (namely Fukushima, Miyagi and Iwate Prefectures) as well as Tochigi and Ibaragi Prefectures ${ }^{2}$. The performance of the model is discussed through comparison of estimated PCLR and index of industrial production in each prefecture. This type of analysis in the case of the Great East Japan Earthquake was introduced in Kajitani et al. (2013b), but this study employs the most updated business distribution data (Ministry of International Affairs and Communications, 2013 (survey year: 2009)), which is more consistent with the business condition at the time of March 11, 2011.

\footnotetext{
1 In Mackenzie et al (2012), direct impacts are determined as production decrease due to the destroyed or partly damaged facilities and indirect impacts are production losses due to the intermediate and final demand changes.

2 In fact, more prefectures suffered direct damages, including Chiba, Aomori and Nagano prefectures. These prefectures should also be analyzed in a similar manner.
} 


\section{DAMAGE TO INDUSTRIES CAUSED BY THE GREAT EAST JAPAN EARTHQUAKE AND AN OUTLINE OF THE CAPACITY LOSS ESTIMATION MODEL}

\subsection{Industrial Damages Caused by the Great East Japan Earthquake}

It has been reported that various types of business facilities located over a wide area were damaged by the Great East Japan Earthquake and subsequent tsunami. For example, on March 15 the Nikkei, Inc. (2011) introduced the status of damage incurred by many industrial sectors, including automobiles, electronics and materials. Even where the buildings did not collapse, production in many industries was stopped due to damage to non-structural facilities such as pipelines and storage tanks. Damage to such facilities was caused by earthquake ground motion.

In the regions affected by tsunami, production was stopped both by the inundation of buildings and facilities, and by the inflow of debris. Moreover, production in industrial sectors was hindered by the tie-up of logistics, the loss of raw materials for production, the loss of employees and various other conditions.

The subsequent nuclear accident also significantly affected the industries. The impact of the nuclear accident continued after initial occurrence, through energy shortages and the implementation of restrictions on exports of agricultural and fishery products produced in the radiation-contaminated areas. Production capacity of businesses located near the site of the nuclear accident was thought of as almost completely lost. Specifically, the residents living within a $20-\mathrm{km}$ radius of the site were required to evacuate on March 12, 2011, and residents living 10 $\mathrm{km}$ around the evacuation radius were required to take shelter indoors from March 16, 2011. In the aftermath, the scheduled evacuation areas were determined based on measured radiation levels, and the residents in those areas were recommended to relocate outside those areas within a month (Ministry of Economy, Trade and Industry, 2012).

Outages of lifelines, such as electricity, water and gas (Tohoku Electric Power Company, 2011; Tokyo Electric Power Company, 2011; Ministry of Health, Labor and Welfare, 2011; Japan Gas Association, 2011), are also assumed to have caused a decrease in production capacity. The total number of households, which experienced an electricity outage, stands at 4.86 million (as of April 
7) in the supply area of Tohoku Electric Power Company and about 4.05 million in the supply area of Tokyo Electric Power Company (as of March 11, 2011). In the Tohoku region, the number of households without power decreased to about 320,000 one week after the event, and these were all located in the regions inundated by the tsunami. The water supply to 1.87 million households at maximum and over 2.26 million households in total was required to be recovered due to successive aftershocks (Report No. 116 in Ministry of Health, Labor and Welfare (2011)). The water supply to around 240,000 households was still under recovery as of April 1, but the water supply was mostly restored within about 3 weeks. The number of households which lost their supply of city gas was 460,000 at its highest point (March 13,2011), which is a relatively small number compared to the cases of electricity and water supply loss. This is because the installation rate itself is low in the Tohoku region. However, the recovery rate was also limited; supply had been recovered for only $32 \%$ of all affected households by March 31. In Miyagi Prefecture, 330,499 households required the recovery of gas supply, but by March 31 only 66,918 had been restored.

In this way, various types of damage, which could affect production capacity, were observed in the Great East Japan Earthquake. Sources of hazards that trigger damage can be classified into three categories: earthquake ground motion, tsunami, and nuclear accident. These hazards may reduce the production capacity depending on the vulnerability and resilience characteristics of each sector. Long-term and wide-area lifeline (electricity, water and gas) disruptions could cause significant loss of production capacity for the businesses affected even though the facilities themselves were not damaged. Other factors, such as communication and transportation damages, could also reduce production capacity, but these are not considered in this research.

\subsection{On the Production Capacity}

As briefly discussed in the introduction, production capacity is defined as the maximum production level if all the resources originally endowed are utilized. These endowments normally consist of capital, land and labor. The focus of this research is production facilities included in capital, which tended to have a dominant impact on the production capacity in the past earthquake disasters in Japan. Thus, other endowments, such as liquid capital, are assumed to be unaffected by the disasters, and substitution among endowments are not considered. As for the intermediate 
inputs, specific intermediate inputs such as electricity, water, and gas can be disrupted, but other intermediate inputs are assumed to be in sufficient supply in this research. In the case where a production function is given to some industry, it can be considered that production capacity is a potential quantity of output calculated from the production function where all the available endowments and associated intermediate goods are used as input data. Therefore, the specific settings in this research can be updated and generalized by a production function based on more observed data. For example, shortage of employees could have large impacts on production capacity in some of the regions, such as the places where evacuation was conducted due to the nuclear accident; such settings are partly included in this study.

During a disaster, some of the resources, such as production facilities, can be damaged. The production capacity due to facility damage is defined as the maximum production level when all the inputs, except the production facility, are assumed to be in sufficient supply. Therefore, the production capacity can be defined by various damage conditions. Based on the definition by Rose (2004), the production capacity is affected by (direct) damages and higher-order effects. For example, damage to facility due to the seismic ground motion is a (direct) damage, while capacity losses due to lifeline disruption can be the higher-order effect.

Production capacity is different from the concept of output, because production capacity is simply the status of the supply side. However, if production capacity is the main driver of production output, such as in the case where the idle capacity is small and other inputs are in sufficient supply, and there is ordinary demand, a positive relationship can be seen between production capacity and actual production output. Hence, we will compare the estimated PCLR, a standardized version of production capacity loss, with the standardized index of industrial production in order to check the validity of PCLR estimation method. However, when other conditions are dominant for production, such as in the case of large decrease of demand, the relationship between production capacity and production output must be weak. In any case, it makes sense to study which phenomenon took place in the economy after the disaster by comparing estimated PCLR and observed production index.

In fact, there are many variables which affect the production level. As discussed in Hallegatte and Ghil (2008), the existence of the excess capacity and business cycle can affect the remaining production capacity during a disaster. Excess capacity is the production capacity that is not used 
for production because of lower demand. During a disaster, the excess production capacity before the disaster can be utilized to compensate for capacity losses. Our later analysis does not consider the effect of this type of adjustments. To incorporate the effect of excess capacity, it is necessary to observe when and what types of sectors under some conditions, tend to utilize this excess capacity.

The assumption that intermediate goods, except lifelines, are sufficiently supplied could also influence the difference between the estimated PCLR and the actual production index. In the Great East Japan Earthquake, supply-chain disruption affected the industries all over Japan. This became a problem especially in the places where direct damage was small. Our assumption that PCLR is the main cause of production decrease still remains only in the area severely affected by direct damage. The case study results in a later section could be utilized to infer the impact of the supply-chain impacts and other possible reasons, by verifying the difference between the estimated PCLR and actual production index.

\subsection{Outline of PCLR Estimation in This Research}

Hazard, exposure and vulnerability are often given as the basic elements which comprise disaster risks. For example, the United Nations Department of Humanitarian Affairs (UNDHA) (1992) summarizes the technical terms on disaster risk and proposes that disaster risk can be defined as: "expected losses (of lives, persons injured, property damaged, and economic activity disrupted) due to a particular hazard for a given area and reference period. Based on mathematical calculations, risk is the product of hazard and vulnerability." Here, "lives, persons, property and economic activity" are classified as "elements at risk", which are defined as "the population, buildings and civil engineering works, economic activities, public services and infrastructure, etc. exposed to hazards." In other words, "elements at risk" are equivalent to the exposure to risk. To define risk more rigorously, it is necessary to consider the concept of probability and uncertainty, but hazard, exposure and vulnerability are the widely accepted concepts that constitute risk.

Figure 1 illustrates the basic concepts of hazard, exposure and vulnerability. In this paper, natural phenomena such as tsunami are considered as hazards, and the exposures are the population resident within and properties located in the areas overlapping with hazards. The extent of damage is determined by the vulnerability of the businesses which are exposed to these 
hazards. Figure 1 shows an example distribution of two types of exposures with different vulnerabilities (high vulnerability and low vulnerability).

On the other hand, the ability of a business to recover from or reduce losses after incurring physical and functional damages to systems can be defined as resilience. For example, the remaining amount of production while under lifeline disruption and the speed of recovery for damaged facilities depends on this resilience characteristic. In this way, the extent of damage is determined by hazard, vulnerability, exposure and resilience.

Classifying risk in this way is also effective in summarizing the necessary data and procedures of PCLR assessment in this research. For example, hazards in this research are derived from information on earthquake ground motion, tsunami inundation and evacuation areas due to the nuclear accident. Exposures are the businesses located in the areas which may be affected by hazards. Damages can be determined by the vulnerability of exposures against a certain level of hazard. For example, the functional fragility curve (Nakano, 2011), estimated from business survey data on past disasters, is applied in order to obtain information on vulnerability to facility damages caused by earthquake ground motion. The functional fragility curve was not developed using traditional damage classifications based on asset value, but rather by the functional level of production capacity.

In fact, the PCLR data for the functional fragility curve is obtained from the maximum production level under the facility and employee conditions after the 2004 Chuetsu Earthquake. The inputs for production, such as lifelines and other intermediate goods are assumed to be sufficient. Therefore, shortages of employees could affect PCLR. However, we observed that the capacity losses are primarily determined by facility damage, as a result of checking a similar question and result to PCLR due to the facility damage only, where the employees are assumed to not be affected by the earthquake. In a current study, PCLR due to "facility damage" is used for the output of the functional fragility curve, but the effect of employee and more rigorous functional form of PCLRshould be discussed in a future work.

From the resilience aspect, the recovery level of production capacity rate ((hereinafter referred to as "PCR") is estimated using information on lifeline (electricity, water and gas) disruptions and the recovery of facilities. For this purpose, this paper adopts the lifeline resilience factor, developed in previous studies (Kajitani and Tatano, 2009) in parts of the affected areas in the 
Great East Japan Earthquake.

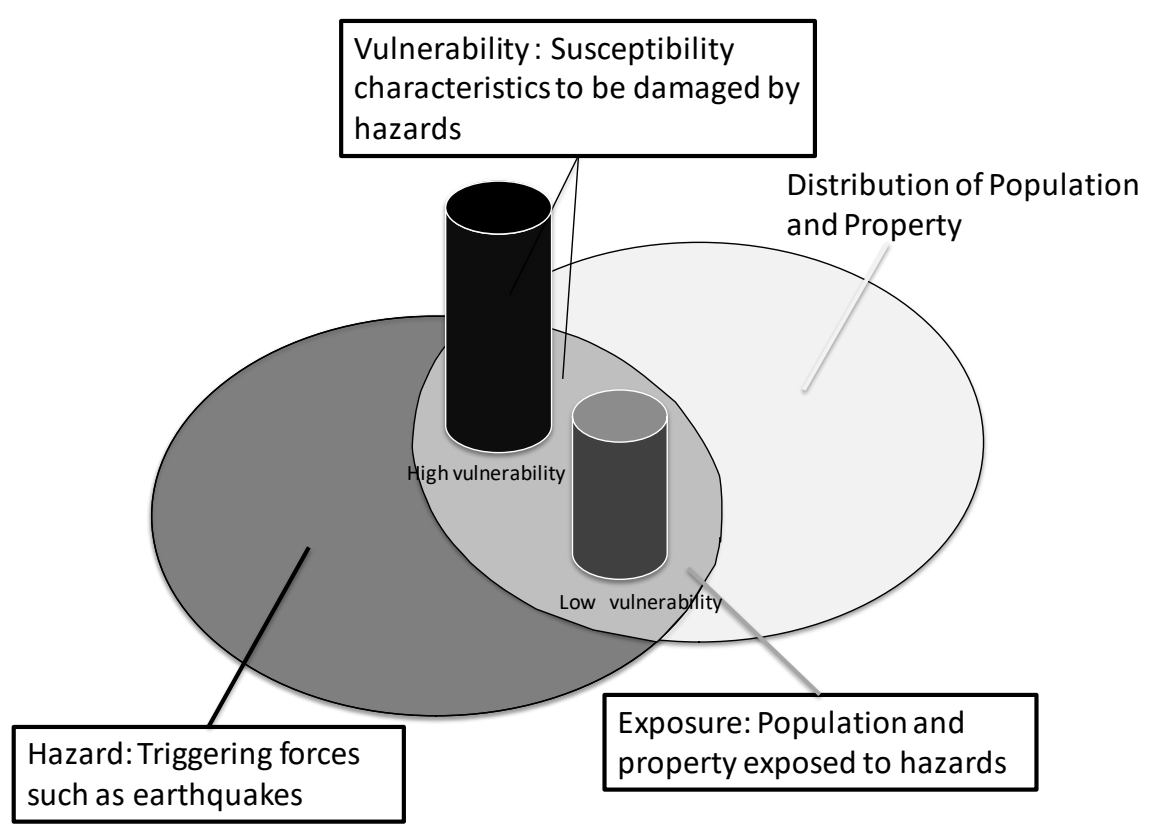

Figure 1. Elements of disaster risk.

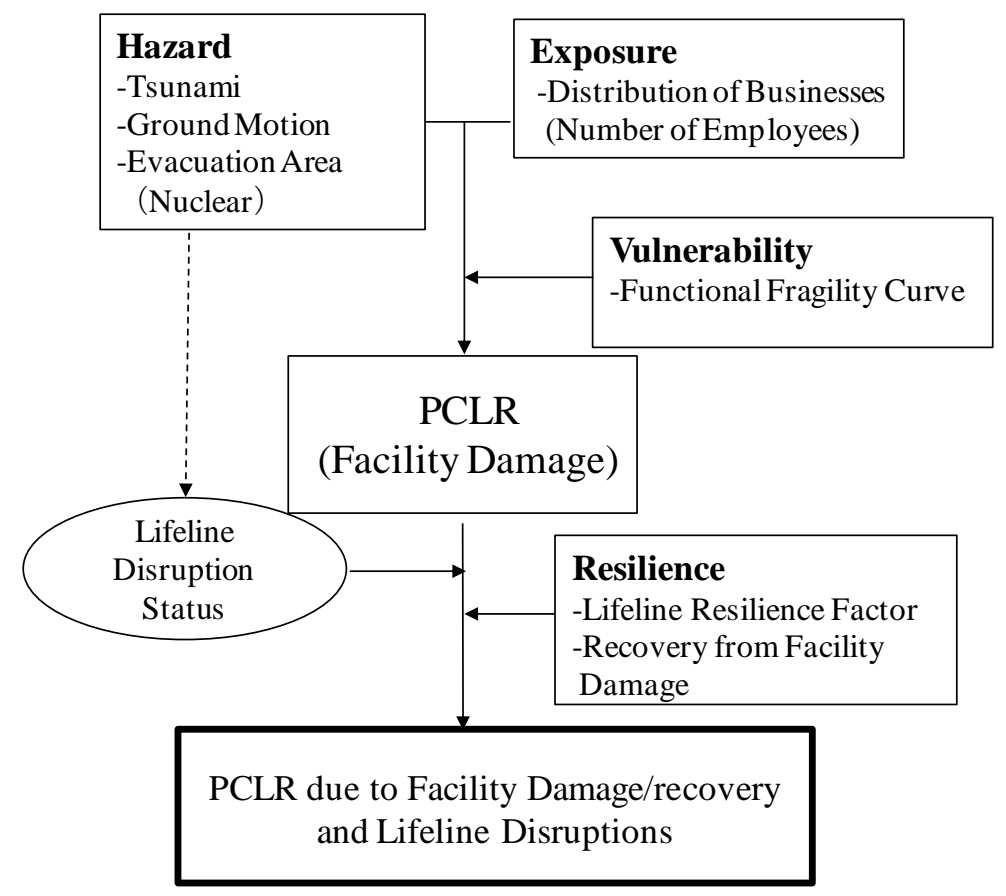

Figure 2. Analytical procedure in this paper. 
Figure 2 depicts the outline of the analytical procedure used in this paper. In the final stage, PCLR (or PCR obtained by 1-PCLR) is derived, with consideration of damage to and the recovery of facilities and lifelines. Further details with practical data sets are given in the next section.

\section{METHODOLOGY TO ESTIMATE PRODUCTION CAPACITY}

\subsection{Hazard and Exposure Assessment}

As is given in Figure 2, the estimation of capacity loss begins with an estimation of hazards, focusing especially on the earthquake, tsunami and nuclear accident examined in this study. As for the earthquake ground motion, a Spectral Intensity (SI) map, interpolated in a 250-meter grid scale by Suetomi and Fukushima (2011), is employed. The original data sources are the observed ground motion data recorded at 534 observatory points, which are operated by the National Research Institute for Earth Science and Disaster Prevention (NIED) (435 points), Ministry of Land, Infrastructure and Transport (MLIT) (13 points), and Yokohama city (86 points).

The tsunami inundation area was estimated by the Geospatial Information Authority of Japan (2011), based on aerial orthophoto images. Modified data from University of Tokyo (Earth Environment Engineering Group, 2012), intended for use by general geographic information systems, is employed in this research. The impact of the nuclear accident was accounted for by assuming that industrial activities stopped completely within the mandatory evacuation zone (within a radius of $20 \mathrm{~km}$ from the site) at the first stage of the accident. This represents the minimum impact of the accident and further study is required for a more detailed analysis.

An overlapping map of the three hazards and a map focusing on the tsunami inundation area in Miyagi and Iwate Prefectures are shown in Figure 3 and 4 respectively. In Figure 3, the severely affected areas, where the SI value is over 80 Kine, are seen in a large part of Miyagi Prefecture, in inland areas of Fukushima and Tochigi Prefectures, and a coastal area of Ibaraki Prefecture. Figure 4 shows how the inundated area spread from Iwate to Ibaragi Prefectures, with a particularly large inundated area identifiable in the southern part of Miyagi Prefecture. 


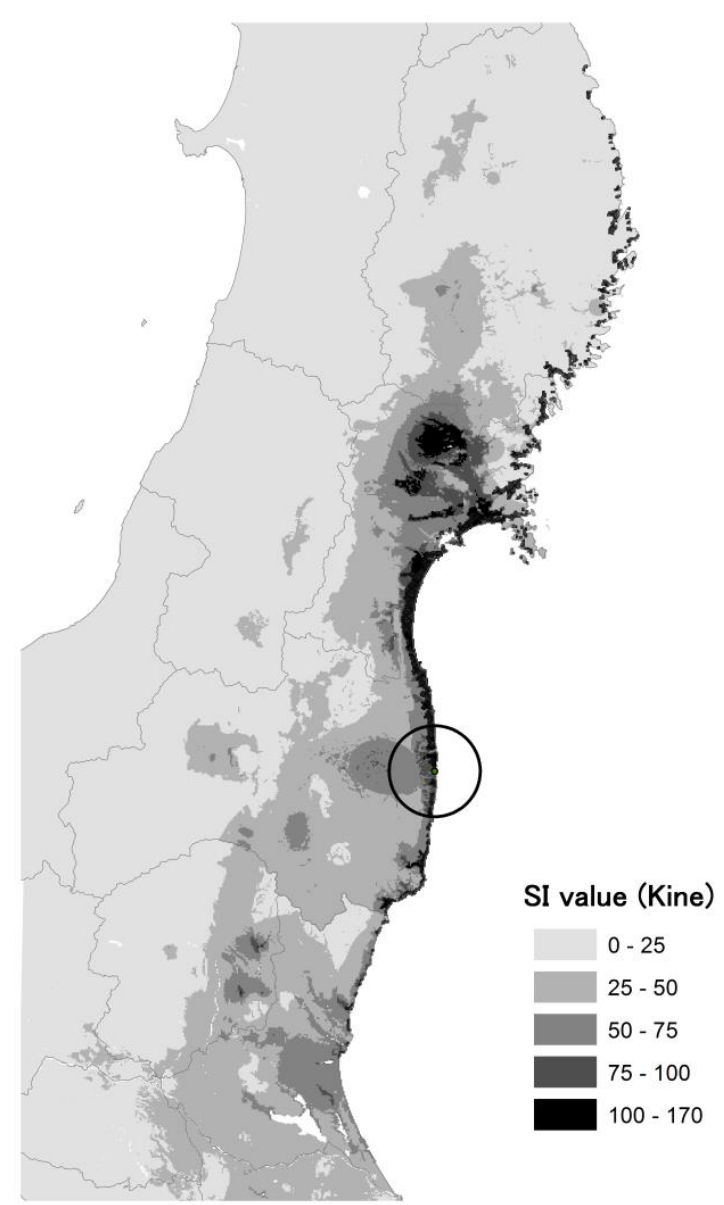

Figure 3. Earthquake ground motion (Spectral Intensity), tsunami inundation area (shaded area along the coastline), and mandatory evacuation zone (circled area). 


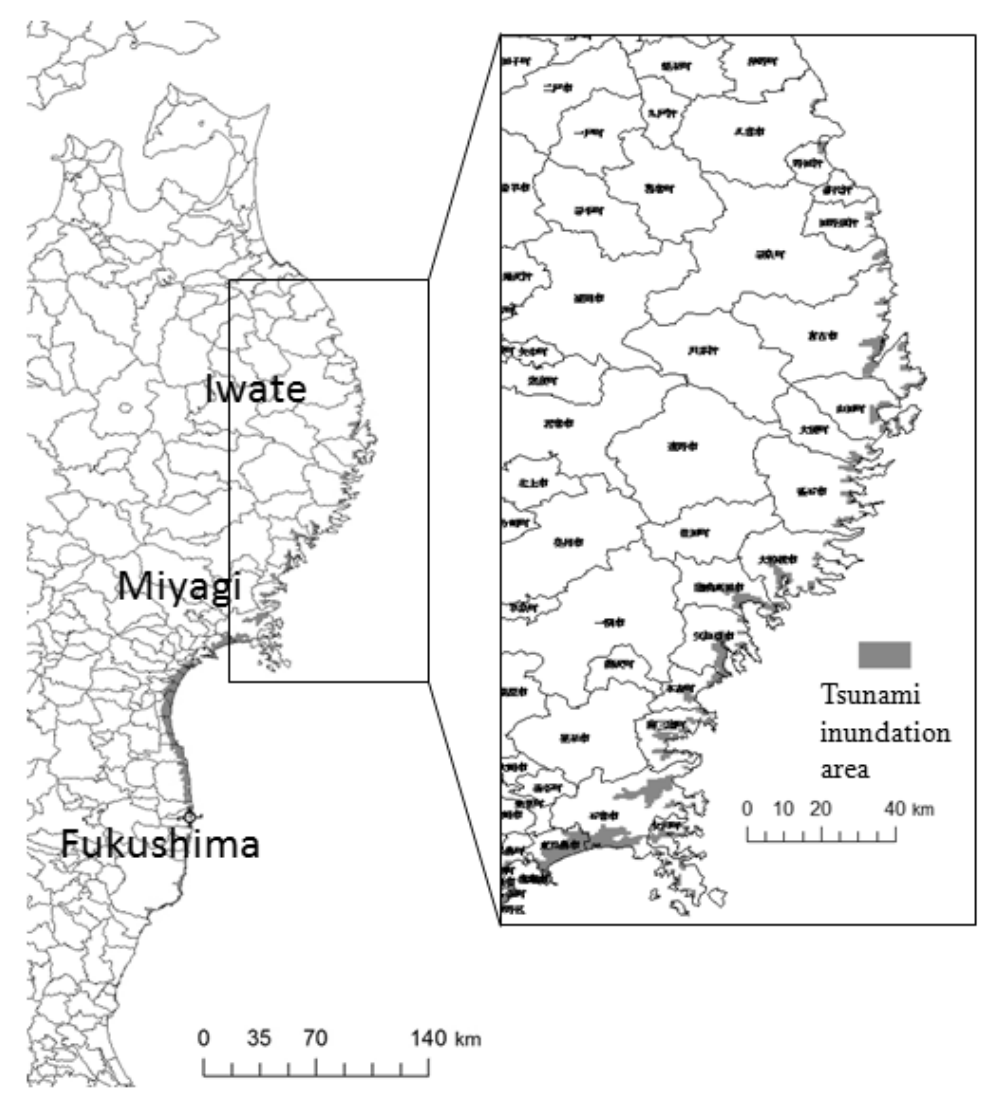

Figure 4. Tsunami inundation areas.

In order to develop information on exposure in this study, data on the spatial distribution of production facilities and their respective production capacities were required, but in principle this type of information is not commonly available. Therefore, this research assumed that the spatial distribution of the number of employees (Ministry of International Affairs and Communications, 2013), which has been plotted onto a 500-m grid scale, is a proxy variable of production capacity as has been assumed in Chen (1996). The classification of industrial sectors is given in Table 1, which is consistent with the lifeline resilience factor and the index of industrial production used in the latter part of this paper. As an example, all the businesses around Miyagi Prefectures are given in FIGURE 5. To integrate the hazard and employee information, all the hazard information was aggregated to the same spatial scale as the employee map, which is on a 500-m grid scale.

\subsection{Vulnerability Assessment of Industrial Facilities}




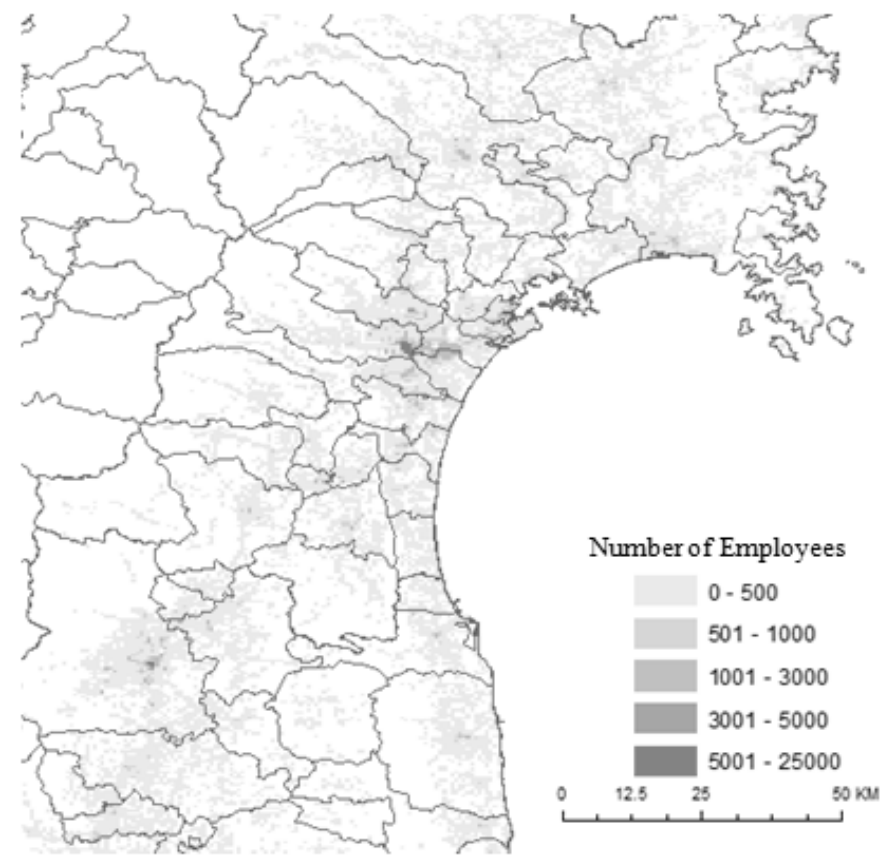

Figure 5. Distribution of businesses around Miyagi Prefecture.

Table 1. Classification of industrial sectors.

\begin{tabular}{cc}
\hline Mining & Electrical Machinery \\
Construction & Information-Communication Equipment \\
Food & Electronic Parts/Devices \\
Apparel \& Textile & Transport Equipment \\
Wood \& Wooden & Precision Machinery \\
Products & Other Manufacturing \\
Paper-Pulp & Communication \\
Chemicals & Transportation \\
Refineries \& Coal & Wholesale \& Retail \\
Glass/Stone/Clay & Financial, Insurance \\
Steel & Real Estate \\
Non-ferrous & Medical Service \\
Metal Products & Other Services \\
General Machinery &
\end{tabular}


Considerable research has been conducted on estimating damage to artificial structures in disasters. In cases of the earthquake-related disaster, in particular, much research has been conducted on the fragility curve, which describes the relationship between the size of earthquake ground motion and damage probability (e.g. Shinozuka, 2000). Normally, the damage status in the fragility curve function is based on physical damage or nullified financial value. To estimate capacity loss, however, what is required is data on the remaining production level.

To tackle this problem, Nakano (2011) developed the functional fragility curve, which captures the relationship between earthquake ground motion and damage to production capacity. The functional fragility curve is estimated based on the results, obtained via questionnaire, of an investigation into PCLRs of businesses after the 2004 Chuetsu Earthquake. The value of PCLR used in this research mainly originates in the recovery situation of the relevant factor of production, such as buildings, production facilities, employees. Those samples which faced external factors, such as the shortage of raw materials and the cessation of lifelines, are not included. As is discussed in Section 2, this research described PCLR as calculated by functional fragility in terms only of production facility damage. Two types of functional fragility, for manufacturing and non-manufacturing sectors, are available and both were used in this study.

Damage modes in this functional fragility curve are classified into one of three categories, $\boldsymbol{d} \in\{\boldsymbol{I}, \boldsymbol{I I}, \boldsymbol{I I I}\}$, which have ranges of production capacity damage level as shown in Figure 6. The range of damage categories is expressed as $\boldsymbol{D}_{\boldsymbol{d}}$, where $0<\boldsymbol{D}_{\boldsymbol{I}} \leq 1 / 3,1 / 3<\boldsymbol{D}_{I I} \leq 2 / 3,2 / 3<\boldsymbol{D}_{I I I} \leq 1$. If PCLR in the same damage category is assumed to be equally likely to occur under the ground motion index $S I^{3}$, the relationship between the cumulative distribution and the damage level can be illustrated as shown in Figure 7. In Figure 7, the size of the shaded area becomes the expected value of PCR $\boldsymbol{F}(\boldsymbol{S I})$. Therefore, expected value $\mathrm{E}(\boldsymbol{F}(\boldsymbol{S I}))$, can be expressed by summing up two trapezoids and one triangle area as follows:

$$
\begin{aligned}
\mathrm{E}(\boldsymbol{F}(\boldsymbol{S I})) & =\frac{1}{2}\left(\frac{1}{3}\left(\boldsymbol{F}_{\boldsymbol{I}}(\boldsymbol{S I})+\boldsymbol{F}_{I I}(\boldsymbol{S I})\right)\right)+\frac{1}{2}\left(\frac{1}{3}\left(\boldsymbol{F}_{I I}(\boldsymbol{S I})+\boldsymbol{F}_{I I I}(\boldsymbol{S I})\right)\right)+\frac{1}{2}\left(\frac{1}{3} \boldsymbol{F}_{I I I}(\boldsymbol{S I})\right) \\
& =\frac{1}{6} \boldsymbol{F}_{\boldsymbol{I}}(\boldsymbol{S I})+\frac{1}{3} \boldsymbol{F}_{I I}(\boldsymbol{S I})+\frac{1}{3} \boldsymbol{F}_{I I I}(\boldsymbol{S I})
\end{aligned}
$$

\footnotetext{
3 In other words, uniform distribution is applied to the range in each category. For example, because functional damage levels $1 / 4$ and $1 / 5$ belong to the same category I, the occurrence probabilities of these are same. The number of categories becomes larger, and more detailed results can be obtained. Due to the limitation of sample number for the functional fragility curve, the three categories are used for now.
} 
That is, the remaining production capacity is given by $\boldsymbol{C}(\boldsymbol{S I})=1-\boldsymbol{F}(\boldsymbol{S I})$.
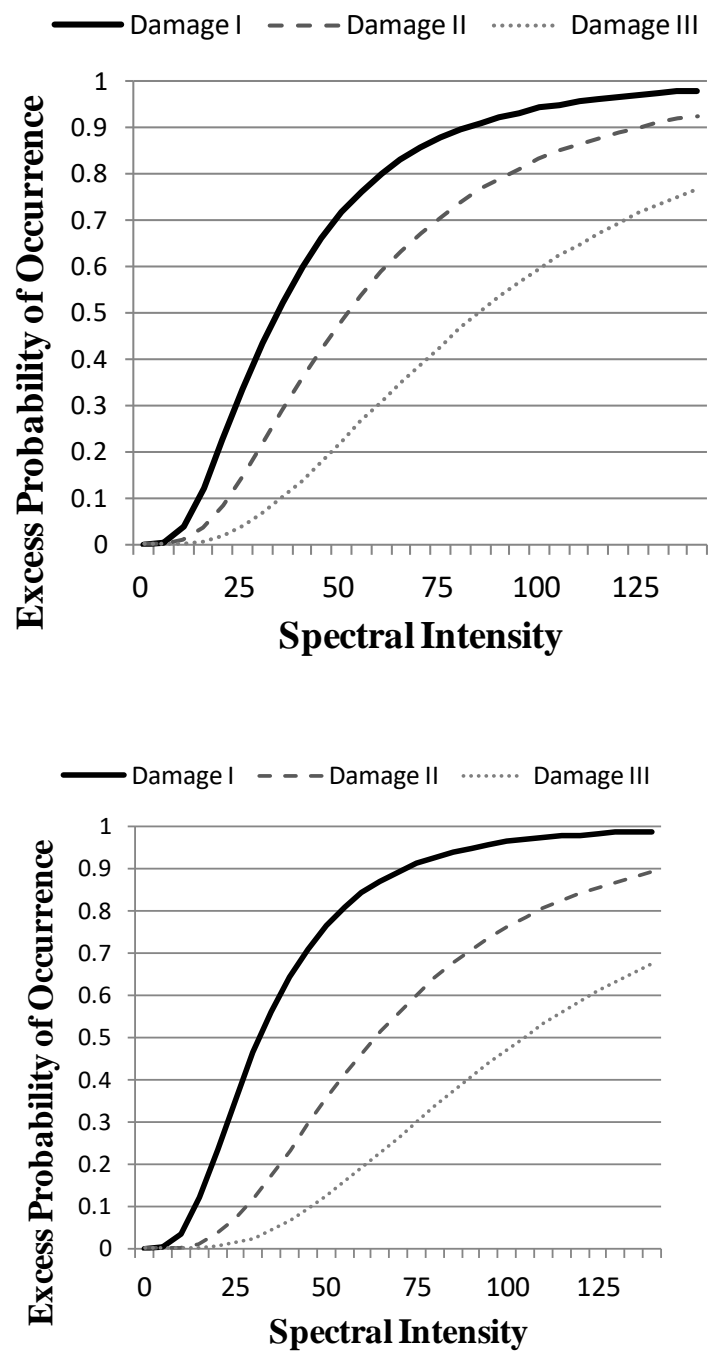

Figure 6. Functional fragility curve for manufacturing (top) and non-manufacturing sectors (bottom). 


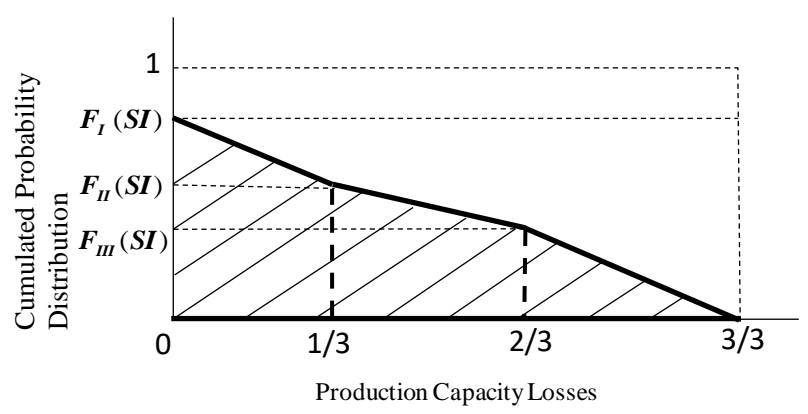

Figure 7. Relationship between production capacity losses and cumulated probability distribution.

In the case of tsunami, as is described in Section 2, even if the inundation height is shallow and a building does not collapse, the industry would still face difficulties in operation due to various other factors, such as debris flows and safety checks on employees. Therefore, PCLR is simply set as 1 for industries located in the tsunami-inundated area, similarly for the case of the mandatory evacuation zone put in place due to the nuclear accident.

In this way, vulnerabilities with respect to three types of hazards have been explained, but careful consideration is still required for the estimation of PCLR where multiple hazards overlap. For such calculations, this study adopted the following procedure to derive sectoral PCLR in different regions.

At first, the smallest area for this study (grid) is set as $\boldsymbol{i} \in \Omega^{s}$, where $\Omega^{s}$ is the set of small regions in the aggregated areas. When the damage level of industry $k$ by a ground motion $S I_{i}$ is determined by $\boldsymbol{F}^{k}\left(\boldsymbol{S I}_{i}\right)$, and the tsunami inundated area and mandatory evacuation zone ratios are $\boldsymbol{T A}_{i}$ and $\boldsymbol{P} \boldsymbol{A}_{i}$ respectively, then PCR $\boldsymbol{C}_{i}^{k}$ is calculated as follows:

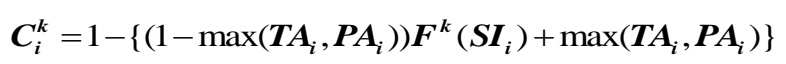

Damage caused by ground motion is basically overwhelmed by tsunami inundation and the impact of nuclear accident. In a more detailed manner, the overlapping areas of tsunami inundation and mandatory evacuation should be identified in order to evaluate the synergistic effects of these two hazards, but this type of manipulation becomes necessary only in a very limited grid area. Therefore, this study simply assumes that the hazard with the larger area size in the grid determines the size of the no production area. 
Secondly, the distribution of exposure (number of employees) for industry $k$ in a small area is expressed as $\boldsymbol{N}_{i}^{k}$. Then, total PCR $\boldsymbol{T C} \boldsymbol{c}_{s}^{k}$ in the target area $s$, is determined as follows:

$$
T C_{s}^{k}=\frac{\sum_{i \in \Omega^{s}} N_{i}^{k} C_{i}^{k}}{\sum_{i \in \Omega^{s}} N_{i}^{k}}
$$

That is, the average of PCRs weighted by the production ability is estimated.

\subsection{Analysis of Resilience}

\subsubsection{Estimating Production Capacity Decrease Due to Lifeline Disruptions}

Even if businesses are affected by the disruption to lifelines, they will try to maintain predisaster production levels to the extent possible. The percentage of remaining production can be subject, however, to businesses' inherent dependence on and adaptive responses to disrupted lifeline systems. These types of remaining production capacity under lifeline disruptions are defined as Lifeline Resilience Factors. In Japan, lifeline resilience factors for 27 industrial sectors have been measured by Kajitani and Tatano (2009), where production capabilities are estimated under 7 different disruption patterns involving electricity, water and city gas.

This research sought to estimate the influence of the lifeline resilience factor on PCR of each industry, and for this purpose, it was necessary to develop a database on the disruption periods of each lifeline in the damaged area. As described in Section 2, lifeline disruption occurred in an extensive area and detailed data on disruption and recovery circumstances on a narrower spatial scale, such as a 500-meter grid, is not available. Therefore, information on lifeline restoration used in this research has been created using the following method.

First, the following data sources were used: for electricity, Tohoku Electric Power Company (2011) and Tokyo Electric Power Company (2011); for water, the Ministry of Health, Labor and Welfare (2011); and for gas, the Japan Gas Association (2011). Judging from the content of these reports, information on lifeline disruption was collected in units of city, ward, town, and village, as the smallest available spatial scale. When there is an expression containing two or more cities, wards, towns, or villages, it is assumed that the same lifeline disruption patterns can be assumed in all the relevant areas. In fact, even if the lifeline stopped in some parts of the areas, such as the information on number of households in the area, it is assumed that total area suffers from lifeline 
disruptions. Therefore, the impact on PCLR by lifeline disruptions in such areas could be subject to exaggerated estimates. On the other hand, there exist some areas where information on lifeline disruptions is not available. In such areas, the impact of lifeline disruptions on production capacity may be underestimated.

Disruption days calculated using data on electricity, water and city gas disruptions are shown in Figures 8, 9 and 10, respectively. It turns out that the areas where lifeline restoration took a significant number of days are concentrated along tsunami-affected shorelines. Apart from the tsunami-affected areas, in most cases it took around 5-10 days for the recovery of electricity supply, and 10-30 days for the recovery of water supply. The city gas system is installed only over a limited area, but in most cases it took more than 30 days for lifelines to be restored.

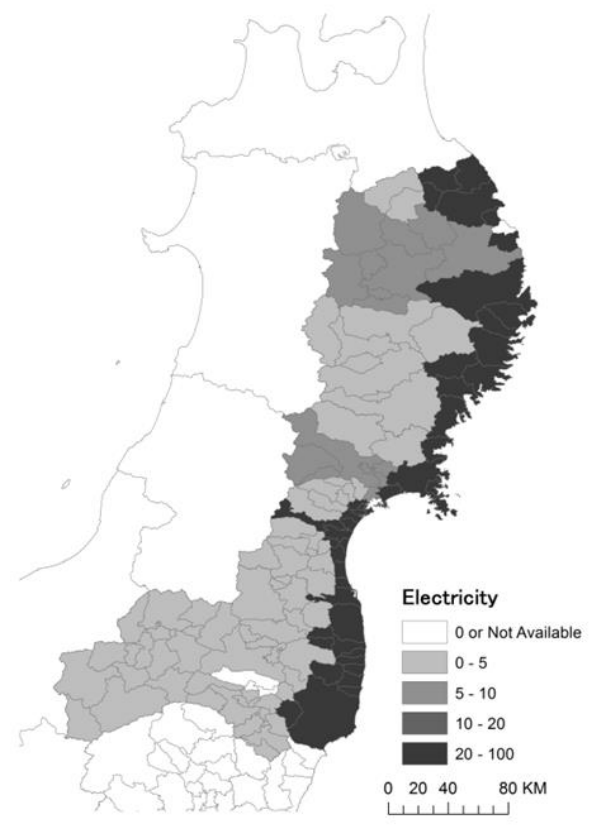

Figure 8. Number of days taken for electricity supply to be recovered. 


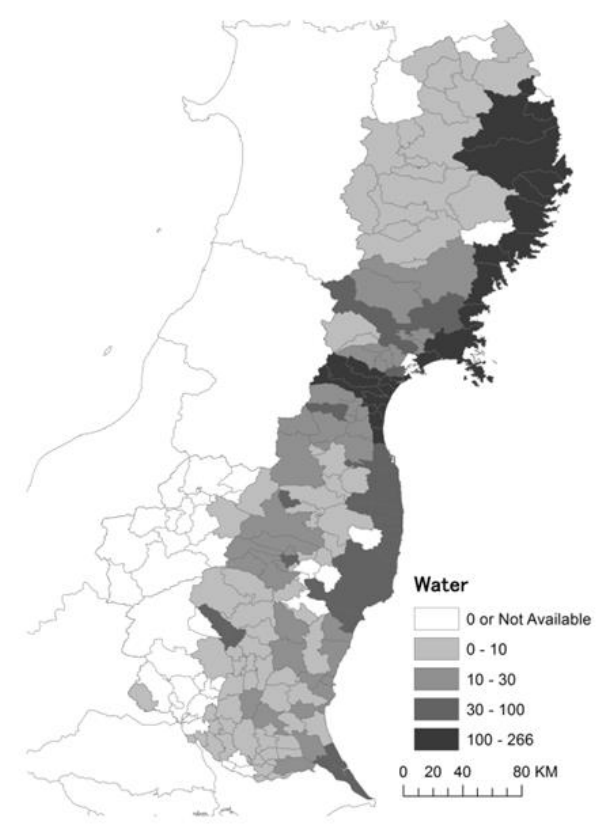

Figure 9. Number of days taken for water supply to be recovered.

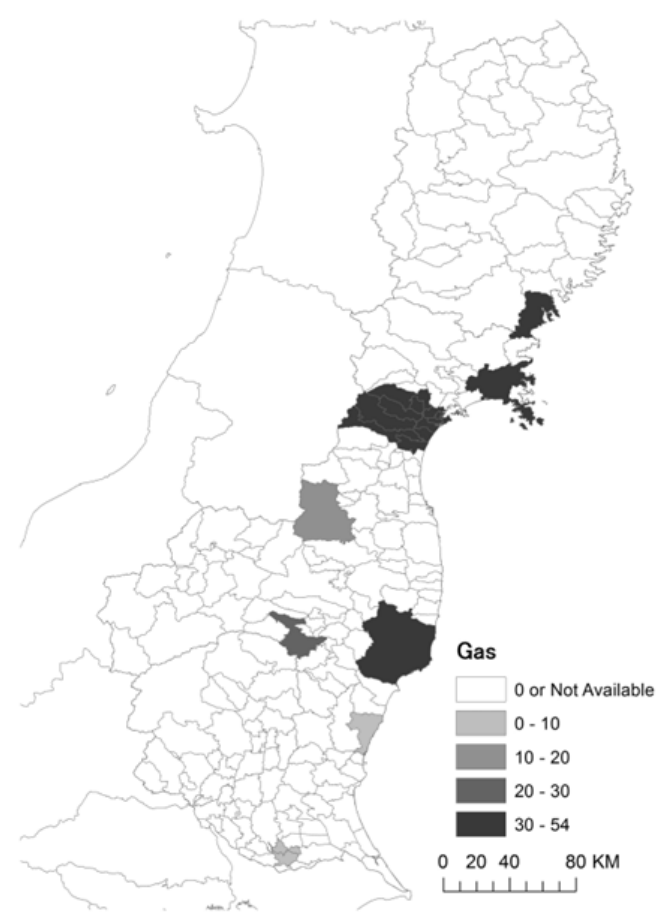

Figure 10. Number of days taken for city gas supply to be recovered. 


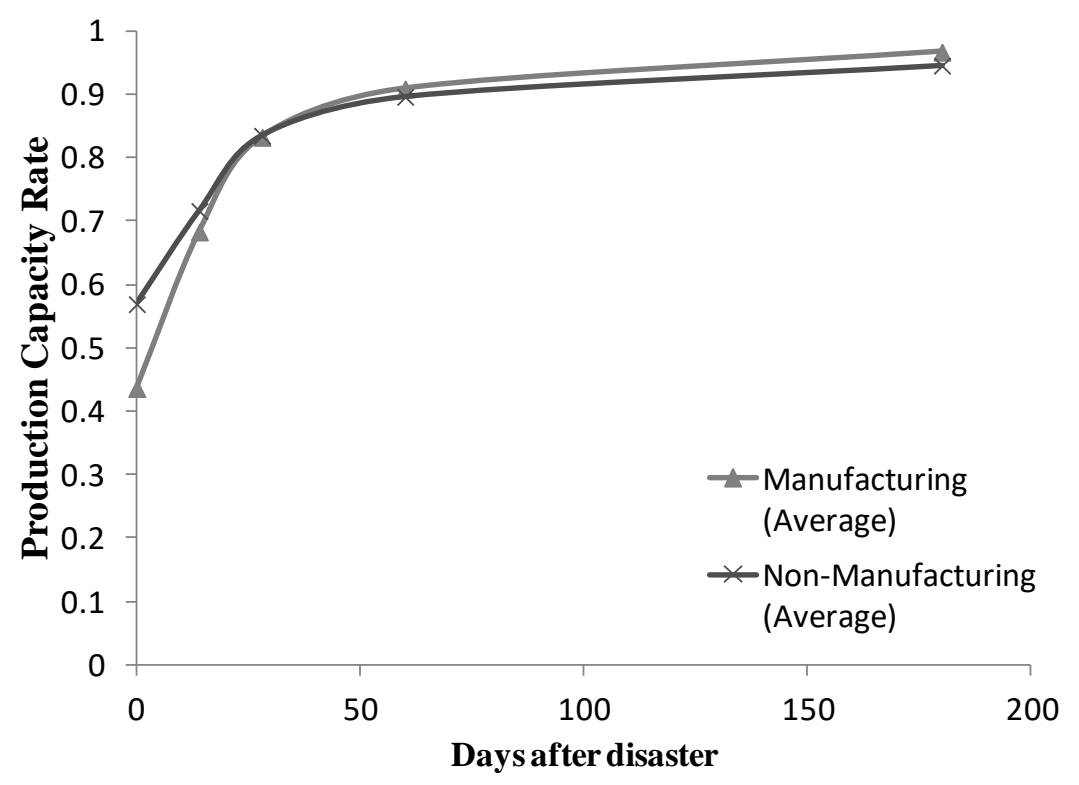

Figure 11. Recovery of PCR.

\subsubsection{Recovery Process of PCR(Facility)}

When estimating production capacity, both immediately after a disaster and during the subsequent restoration period, it is necessary to make assumptions about the kind of restoration activities performed in each company. However, previous research has not included a full examination of recovery models for standard production capacity after a disaster. Therefore, as a tentative recovery model, this research adopted actual post-disaster survey data on the recovery of PCR, taken from the study conducted by Nakano et al. (2011).

The number of businesses surveyed by Nakano et al. was 2669, of which 777 businesses were involved in manufacturing industries, and 1892 in non-manufacturing industries. All businesses were located in Miyagi and Iwate Prefectures. The areas surveyed did not include areas which suffered damage caused by tsunami, or areas subject to mandatory evacuation as a result of the nuclear accident. In other words, the data was obtained from those areas which were mainly affected by earthquake ground motion. In addition, due to facility damage and employee losses are considered to be separate from those losses caused by external incidents such as lifeline disruptions. This is consistent with the definition of the fragility curve introduced in the previous section. 
The average value of PCR of the businesses, which are classified into either manufacturing or non-manufacturing industries, is shown in Figure 11. There are depressions of PCR, a little more than $40 \%$ in manufacturing industries, and a little less than $60 \%$ in non-manufacturing industries. Although the depression in the manufacturing industries is larger, the recovery speed is faster and the average PCR exceeds that of the non-manufacturing industries one month after the disaster. In this study, the restoration process of PCR for each business is defined according to this data, and in order to clarify the relationship between the size of the depression at the beginning (immediately after the disaster) and the recovery process, the following hazard function is used to define the recovery process.

$$
\boldsymbol{C}_{i}^{k}(\boldsymbol{t})=\boldsymbol{C}_{i}^{k}(0)+\frac{\left(1-\boldsymbol{C}_{i}^{k}(0)\right) \exp \left(\boldsymbol{\beta}_{0}+\boldsymbol{\beta}_{1} \boldsymbol{t}+\boldsymbol{\beta}_{2} \boldsymbol{C}_{i}^{k}(0) \boldsymbol{t}\right)}{1+\exp \left(\boldsymbol{\beta}_{0}+\boldsymbol{\beta}_{1} \boldsymbol{t}+\boldsymbol{\beta}_{2} \boldsymbol{C}_{i}^{k}(0) \boldsymbol{t}\right)}
$$

where $\boldsymbol{C}_{i}^{k}(0)$ : PCR immediately after the disaster for industry $k$ located in region $i, t$ : elapsed time after the disaster (days), $\boldsymbol{\beta}_{0}, \boldsymbol{\beta}_{1}, \boldsymbol{\beta}_{2}$ : parameters of explanatory variables. Based on this equation, the decreased production $1-\boldsymbol{C}_{\boldsymbol{i}}^{k}(0)$ recovers steadily as time $t$ increases. There can be other statistical models for expressing the recovery curve. Not only functional forms, but also other explanatory variables, such as the size of business and damages to surrounding infrastructures, should be carefully studied. These investigations are beyond this study.

As a result of the parameter estimation, this study adopts $\boldsymbol{\beta}_{0}=-2.493(-10.47), \boldsymbol{\beta}_{1}=0.089(27.96)$, $\boldsymbol{\beta}_{2}=\mathbf{0 . 0 1 2 ( 1 . 8 0 )}$ for the manufacturing sector and $\boldsymbol{\beta}_{0}=-2.463(-14.54), \boldsymbol{\beta}_{1}=0.083(32.99)$, $\boldsymbol{\beta}_{2}=\mathbf{0 . 0 2 3 ( 4 . 9 6 )}$ for the non-manufacturing sector. Here, the numbers given in brackets are $t$ values, which indicate $\boldsymbol{\beta}_{2}$ in the manufacturing sector is significant at the $10 \%$ level, which is a slightly larger significance level, but other parameters become significant at a level of less than $1 \%$. Because recovery processes can be different within more specific sectors, which use distinct production techniques, further investigations are required in order to develop a better recovery function, including investigations on the different types of functional forms.

The other critical assumption was that PCR in the tsunami-inundated and mandatory evacuation areas have not been considered and are left to future research. In the tsunami-inundated areas, in particular, the recovery of facilities could be affected by the depth of inundation; these types of 
relationships should be examined in subsequent studies.

\subsubsection{The relationship between the recoveries of PCR and lifelines}

In order to estimate PCR, it is necessary to integrate the impact of facility damage and of lifeline disruptions as well as that of their respective recoveries. The effects of combining different sources of damages could be more complex in reality, but Figure 12 gives one of the possible structures that could describe the production capacity recovery behaviors. The PCRs induced by the tsunami and nuclear accidents are excluded in this figure because production capacities are assumed to be lost completely only by the direct impact of each hazard in the period of case study explored in Section 4.

First, the lines in the upper part of Figure 12 explain the combinations of three different damage and recovery patterns: production facility damage, lifeline disruption impact, and recovery from the production facility damage. A typical pattern of lifeline disruption impact, which is based on the values of the lifeline resilience factor, is described in the lower part of the figure. Put simply, lifeline impact is reflected in the remaining production capacity of available production facilities at the same ratio (i.e., the remaining production capacity times lifeline resilience factor). Facility damage follows the process indicated by the flat and thicker dotted line, which represents a case in which there is no recovery of capacity. Production facility + lifeline disruption, as shown by the thinner dotted line, results in a lower production capacity because lifeline impact is reflected in the remaining production capacity of available production facilities at the same ratio (i.e., remaining production capacity times the lifeline resilience factor).

Facility damage + recovery results in a PCR curve, as shown by the smooth increasing curve, and includes the recovery process from the production capacity damage. Furthermore, an example of a case including the influence of lifeline disruption is shown by the thick smooth line. If disruptions to lifelines are recovered, the line falls into agreement with the facility damage + recovery curve. The case of thick line, which denotes facility damage + recovery + lifeline disruption, thereby including all the factors, serves as an estimated value of the final production capacity in this research. In this case, the decrease in production capacity is estimated as the area shaded with diagonal lines in Figure 13. 


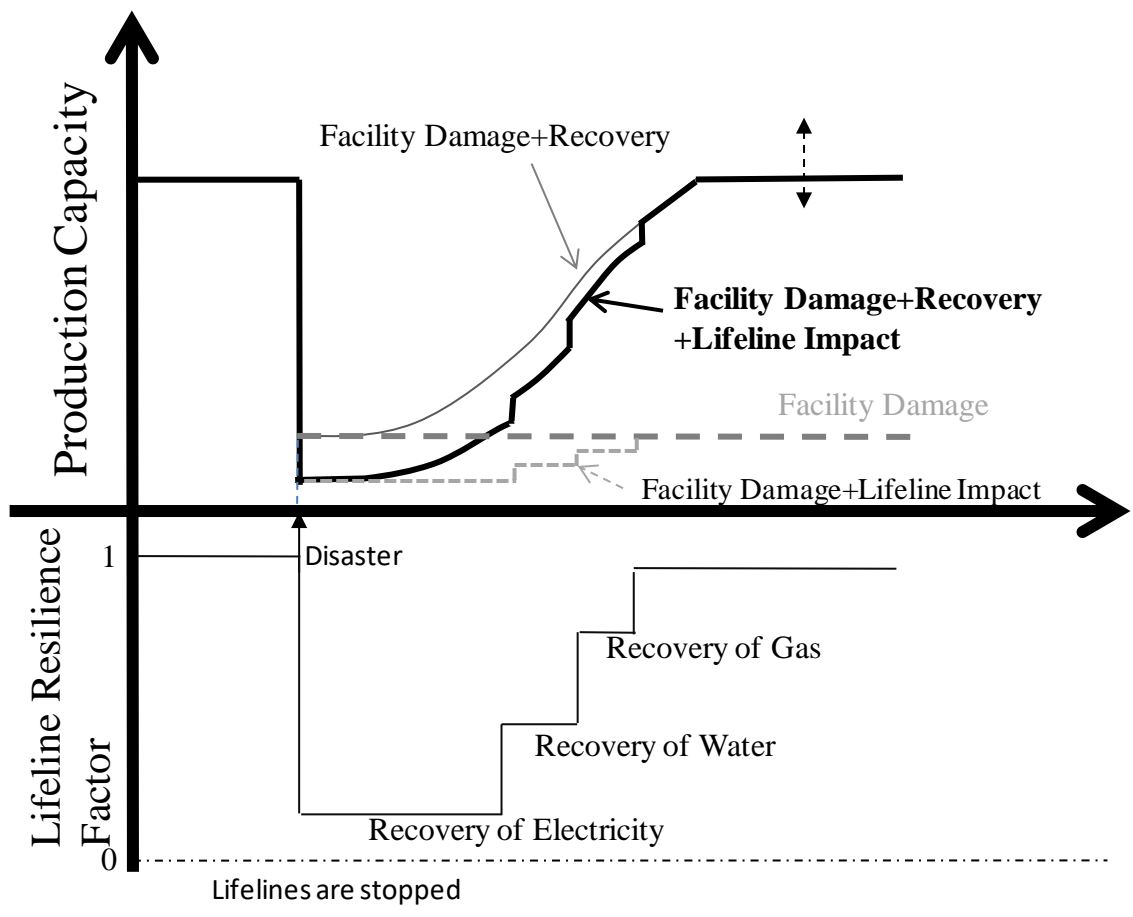

Figure 12. Recovery of PCR considering facility damage and recovery and lifeline disruption impact.

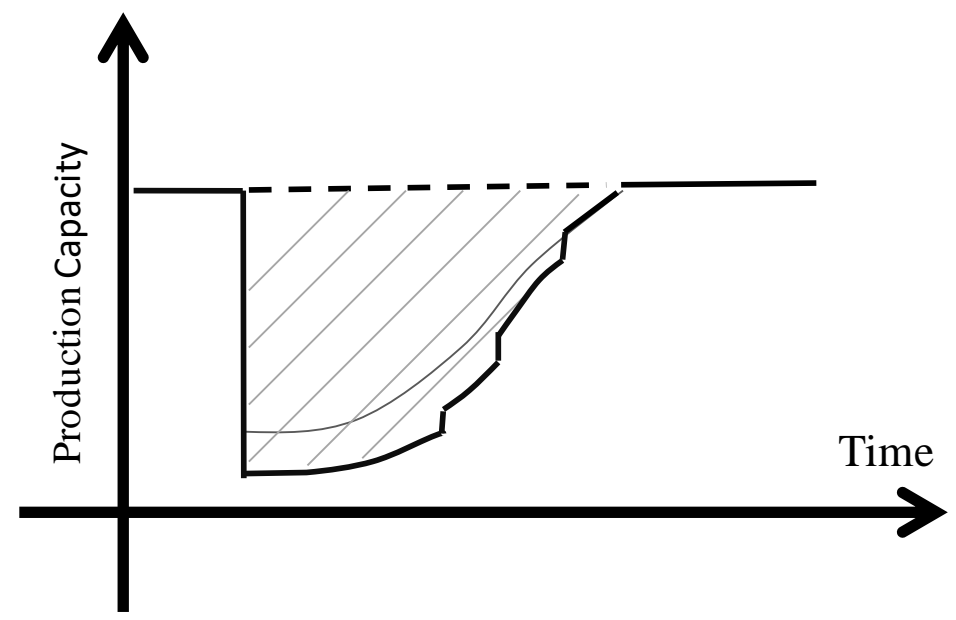

Figure 13. Total production capacity loss.

\section{VERIFICATION OF ESTIMATED RESULTS WITH THE INDUSTRIAL PRODUCTION INDEX}




\subsection{PCLR Immediately after the Disaster}

Those prefectures which were most severely damaged, namely Fukushima, Iwate, Miyagi, Ibaraki, and Tochigi, were selected as case studies for the estimation of PCLR. This section introduces the case of facility damage, which represents PCLR immediately after disaster as shown in Figure 2, and discusses the characteristics of damage distribution in each sector and prefecture at the initial stage. The estimated PCLRs are given in Figures 14, 15, and 16. The results for the case study that considered all hazards (i.e., ground motion, tsunami, and nuclear accident) are given in Figure 14. In contrast, those cases in which only a single hazard is considered (i.e., either tsunami or nuclear accident), are described in Figures 15 and 16, respectively. PCR itself is acquired by extracting the damage ratio from the ideal capacity level of 1 .

Figure 14 clearly shows that the damage rates in Miyagi Prefecture were large across all types of sectors. In particular, the refineries, steel, paper-pulp sectors suffered significant damage in comparison to other sectors. These industries are normally located along coastal areas and could have been damaged mainly by tsunami inundation, as is shown in Figure 15. Elsewhere, the food industry sector in Miyagi Prefecture also lost a significant amount of production capacity, which is similar to the same sector in Iwate Prefecture. In both Miyagi and Iwate Prefectures, facilities related to the fish processing industry are generally located along coastal areas and they represent a large share of production in the food sector. In addition to this, in Iwate Prefecture, the wood and wooden-products industries were also seriously damaged, reflecting the serious damage inflicted upon concentrated industries in this sector, such as those located in Ofunato city.

On the other hand, in Fukushima Prefecture, the largest capacity loss was estimated to be in the chemical sector. PCLR here is estimated at more than $40 \%$, with $8 \%$ of those losses coming from businesses located within a $20-\mathrm{km}$ radius of the nuclear power plant. The circumstances and severity of the damage vary even in two prefectures in the same region, of Kanto (one of the main regions affected by the disaster, along with Tohoku). In Ibaraki Prefecture, damage was large in the nonferrous and in several machinery sectors. On the other hand, capacity losses were relatively small in all sectors in Tochigi Prefecture. Only the chemical sector suffered damage exceeding more than $20 \%$, which was the maximum recorded damage. 


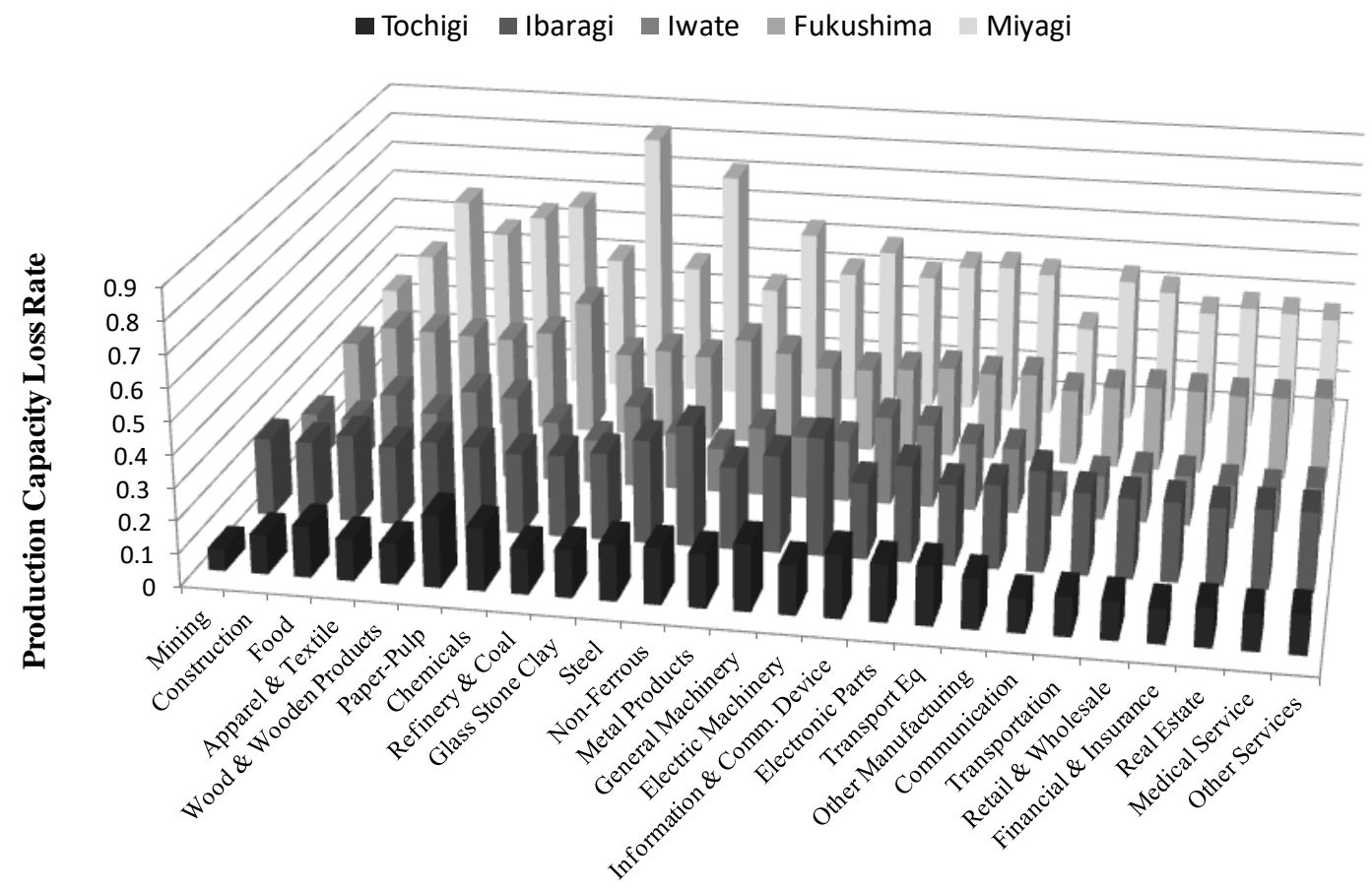

Figure 14. PCLRs caused by three hazards combined.

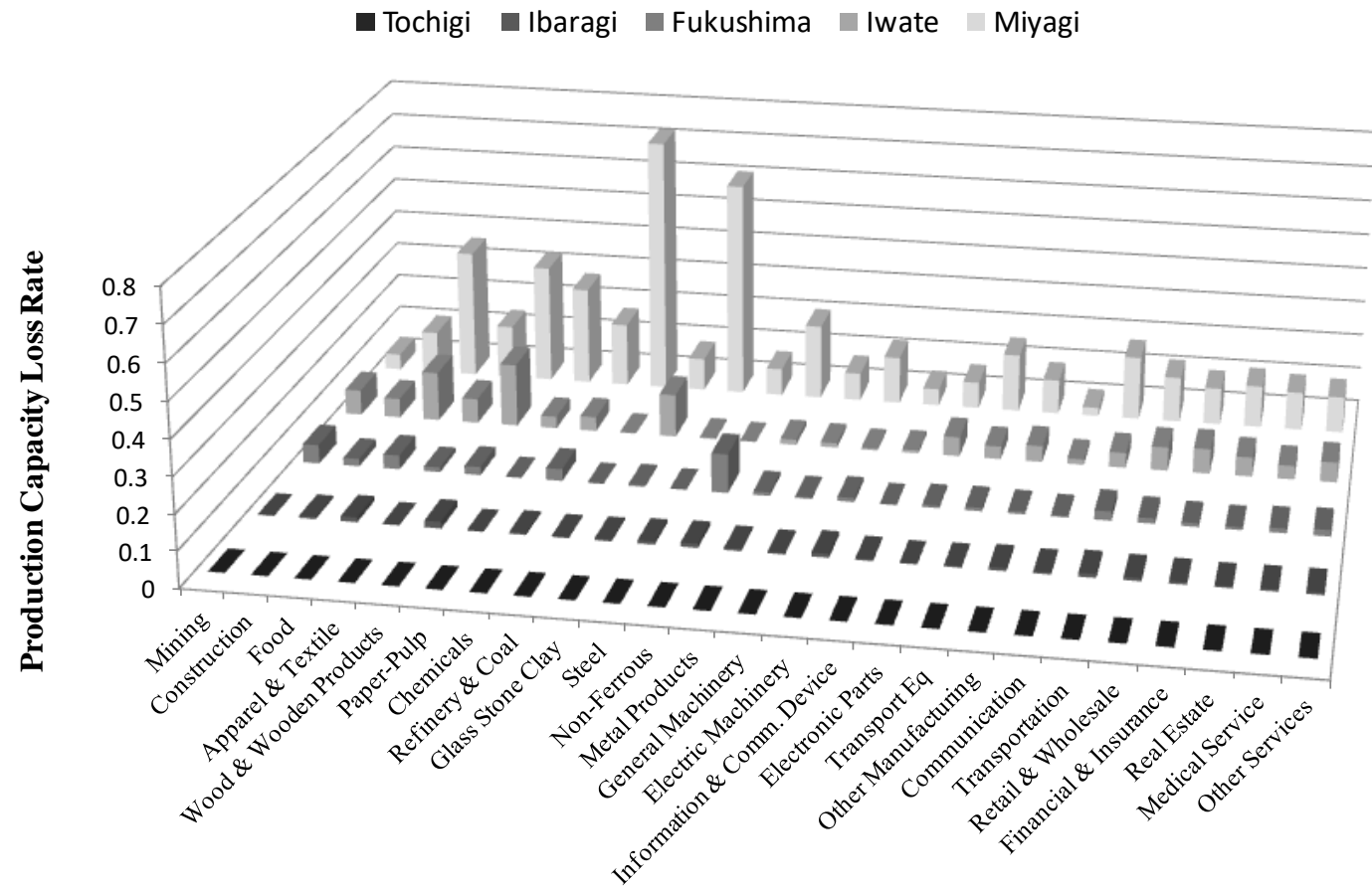


Figure 15. PCLRs caused by tsunami only.

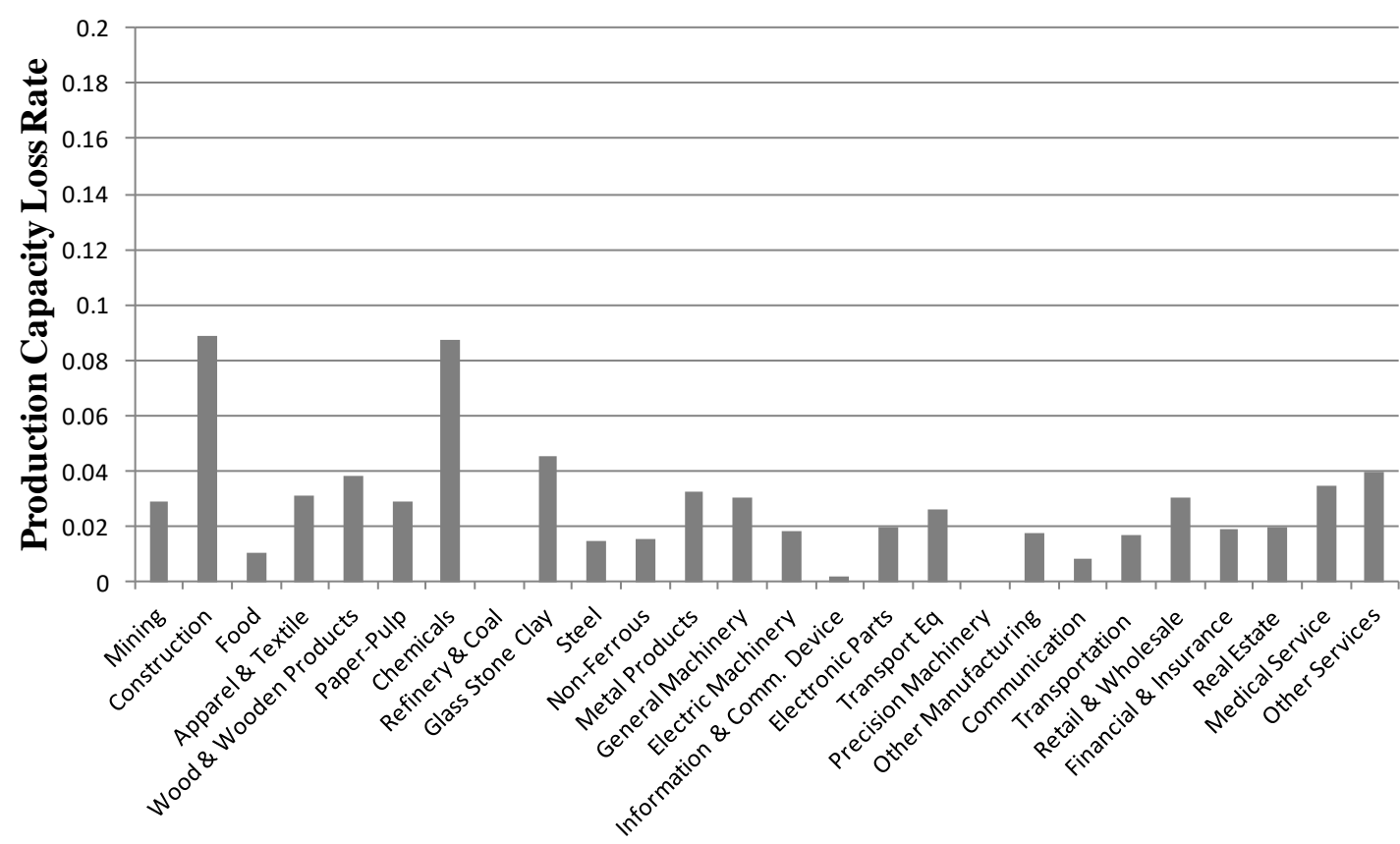

Figure 16. PCLRs caused by the nuclear accident (20-km radius) in Fukushima Prefecture only.

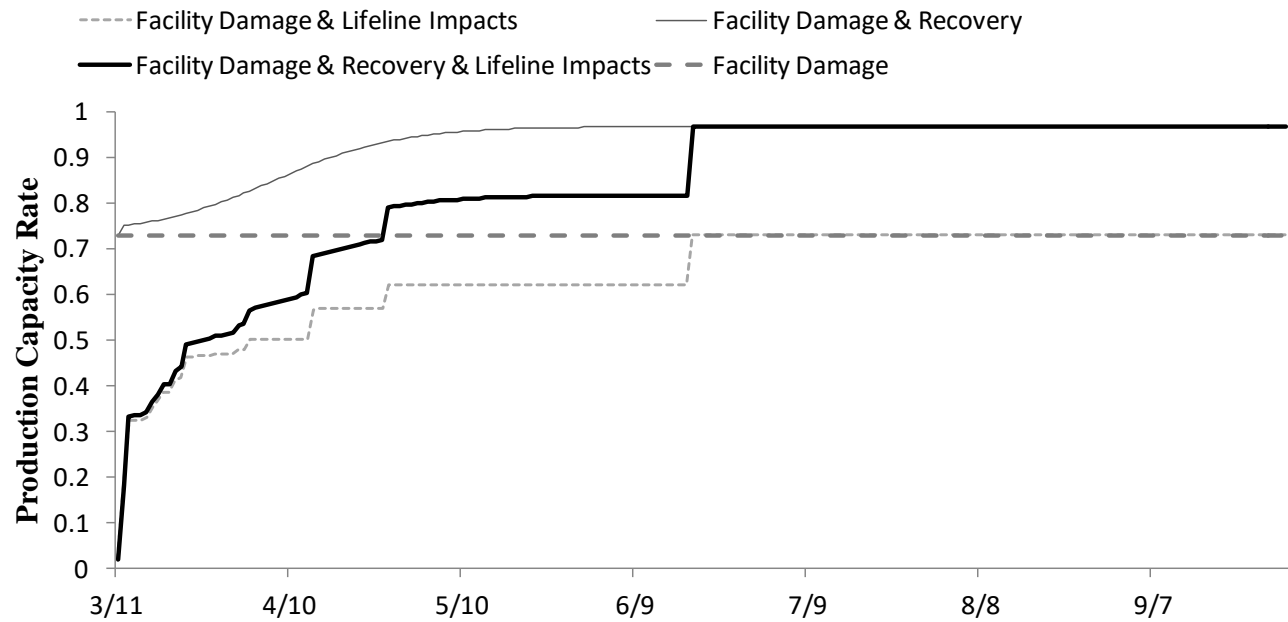

Figure 17. Examples of PCR recovery curves (Transportation machinery sector in Fukushima Prefecture) 


\subsection{Comparison of estimated monthly PCR and index of industrial production (IIP)}

In this section, PCR estimates are compared with the index of industrial production (IIP) for March, April, and May in 2011. In principle, PCR is a different concept from the IIP. PCR represents the maximum possible amount of production, whereas the IIP is estimated based on actual production amounts, which are affected by many factors such as changes in the levels of demand and supply chain disruption. As discussed in subsection 2.2, the basic assumption here is that if the impact of these external factors on the IIP is small, there must be a positive correlation between the estimated PCR and IIP. It is also appropriate to assume that most of the businesses located in the damaged areas will attempt to maintain business continuity to the extent possible, since their goods will likely have become scarce in the market. In some cases, businesses become at risk of experiencing a loss of demand over an extended long period, which may result from other businesses taking over the unfulfilled demand for the supply of goods after the disaster.

In addition, it is also important to investigate which factors affect the extent of production capacity. In this analysis, the respective contributions to PCR of facility damage, facility recovery, and lifeline disruptions are considered. As an example, the analysis of the contribution of several factors to PCR in the transportation machinery sector in Fukushima Prefecture has been illustrated in Figure 17. The four different lines represent the PCR recovery lines for distinct combinations of the contributing factors. The final result is the thick smooth recovery line, which considers all of the factors included in this research. In this line, PCR is only about $10 \%$ on March 11 , the day on which the earthquake hit, but quickly recovers to $30 \%$ in just a few days. After this, PCR recovers to around $80 \%$ by the beginning of June where facility recovery is not assumed, but recovers almost to pre-disaster capacity levels where facility recovery is considered.

The estimates shown in Figure 17 were also carried out for each sector in each region (city, ward, town, village level). This section summarizes the impact on aggregated sectors at the prefecture level in order to provide an overview of the characteristics of the damage caused; a sector by sector analysis follows in the next section. Standardized value-added indicators for index of industrial production are used to aggregate the impact in different sectors (See Figure $18)$.

Comparisons between estimated PCRs and the IIPs for March, April and May in 2011 are 
respectively illustrated in Figures 19, 20 and 21. Here, the seasonally adjusted production index is used and standardized by setting the IIP for February (before the disaster) as 1 to keep the consistency with the definition of PCR. Here, we have an assumption that production capacity change affects the same percentage of seasonal production level. As discussed in subsection 2.2, the excess capacity adjustment is not considered in this case study. One of the reasons for this is that there exists a supply and demand matching problem during the chaotic period after the disaster. A large part of excess capacity could remain unused because of the difficulty of finding business partners or providing specific goods for new partners. However, it is of course, ideal to compare both cases (i.e, with and without excess capacity adjustments). A future task is needed in collecting and identifying how much the excess capacity existed and how it was utilized during the disaster.

To grasp the impact of contributing factors, the results of estimates for the four different cases, corresponding to those shown in Figure 12, are illustrated. To obtain the estimate in March, it was assumed that normal operation was conducted up to March 11. Furthermore, we assumed that 10 out of 31 days' worth of production had already been obtained at the point when the earthquake struck.

Looking first at Figure 19, the estimated PCRs affected only by facility damage in all prefectures in March are overestimated at a rate of around 0.1-0.2, but the results satisfy the conditions for maximum possible production level. On the other hand, in the case of facility damage + lifeline impact, the estimated PCRs become closer to the IIPs. In Miyagi, Fukushima and Iwate Prefectures, the estimated results are slightly lower than the IIPs. This does not satisfy the condition of production capacity. We could consider this error is within an acceptable level as a statistical model, but one of the reasons for this error is that the periods of lifeline disruption are overestimated due to data limitations as discussed in the previous section. The final estimated capacity, which considers also the recovery of the facility, shows no clear change in comparison to the case without recovery. The effects of activities related to facility recovery can be overwhelmed by the impact of lifeline disruptions in March.

In terms of spatial impact, PCRs in Tochigi Prefecture are the most distant from the respective IIPs. This indicates that capacity itself remained in the region, but actual production decreased considerably. There are several plausible explanations for this but verification of those reasons 
fall beyond the scope of this research. However, the following hypothesis may be considered as one such plausible reason. The other four prefectures, aside from Tochigi, are all original regions which caused supply shocks; in these regions, it is mainly raw materials and manufacturing parts that are produced and exported. Such sectors have a particular interest in maintaining production levels as much as possible in order to reduce any economic impact likely to have a wide knockon effect, as well as to prevent customers from changing supply chain routes. While actual production in Tochigi Prefecture decreased, at the same time physical damage to the industries in Tochigi Prefecture was relatively small. Due to the significant damage experienced in the surrounding areas, however, the production amount within Tochigi Prefecture may have decreased as a result of materials shortages and concentration on support activities in those neighboring districts which had suffered severe damage. Similarly, production in other industrial sectors may have decreased, and it is also likely that the scheduled blackouts due to energy shortages would have affected other industries in the Kanto region during March 2011.

In April and May, as described in Figures 20 and 21 respectively, effects of facility recovery play an important role and estimates which do not consider recovery are not particularly suitable applications for capturing PCR. As is similar to the case in April, the results of the final estimates agree with the IIPs.

Overall, by considering facility damage and lifeline disruptions, PCRs are estimated at values close to the IIPs, especially in severely damaged prefectures. This result indicates that the benchmark data sets and hypothesis used for functional fragility curves and lifeline resilience factor are reasonable if the primary sources of the production losses are assumed to be the production capacity losses defined in this research. In addition, it has been demonstrated that the recovery model for a short-term period after the disaster is not particularly significant in estimating PCRs or PCLRs. This is a favorable condition which allows researchers to avoid modeling the complicated recovery patterns of each sector. However, to estimate capacity recovery over the long-term, it is vital that a more general recovery model for facilities be developed. 


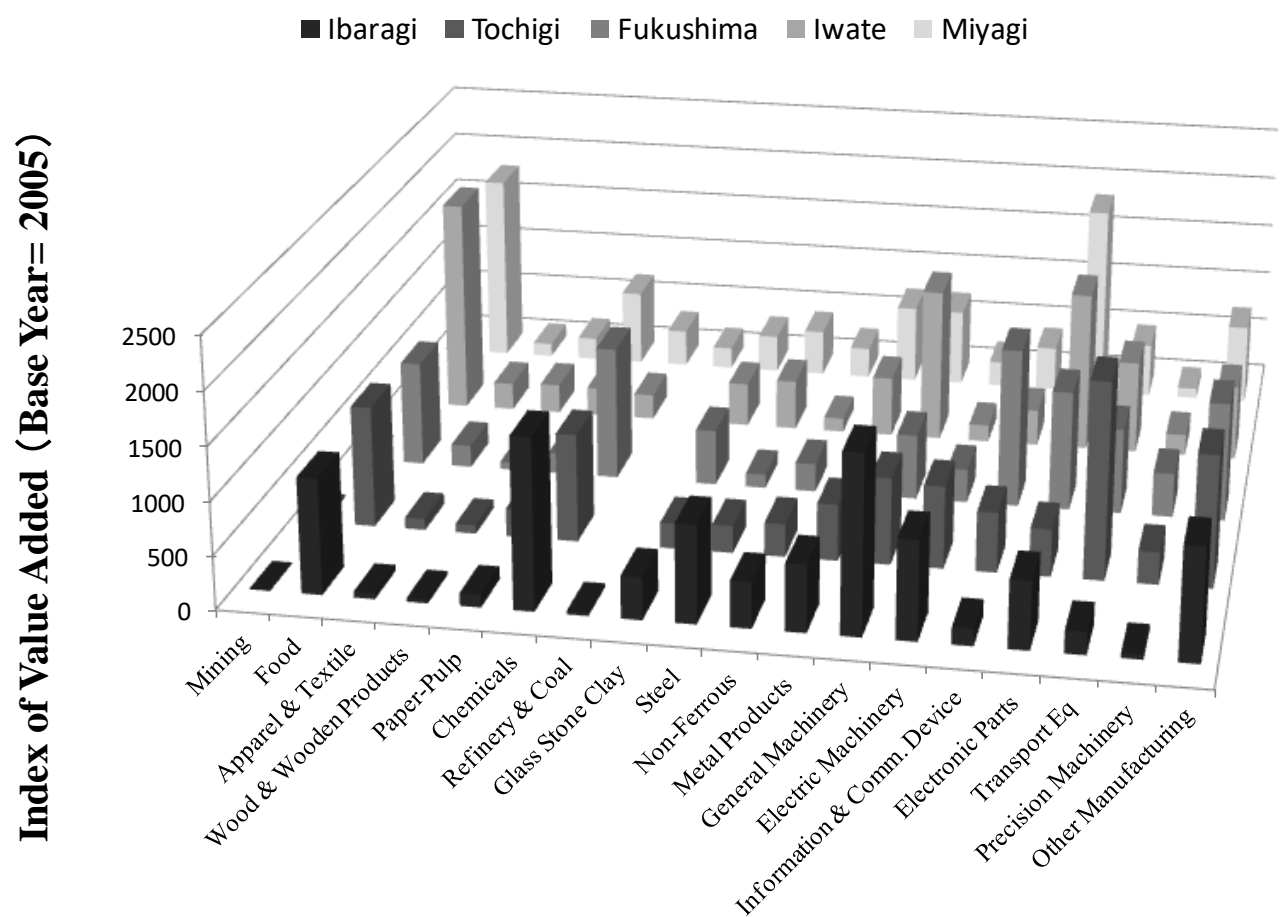

Figure 18. Index of value added used in this study.

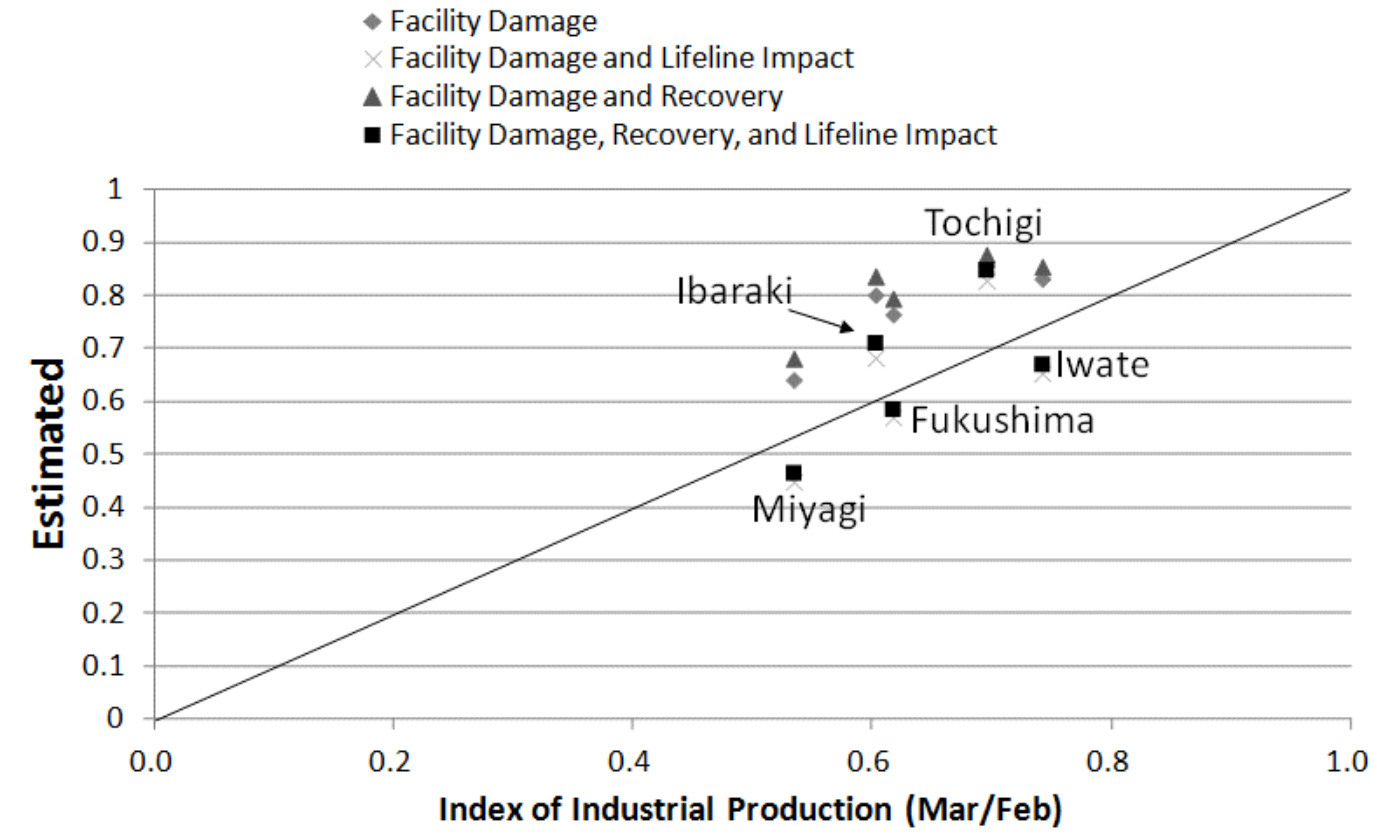

Figure 19. Comparison between estimated PCRs and IIPs in March, 2011. 


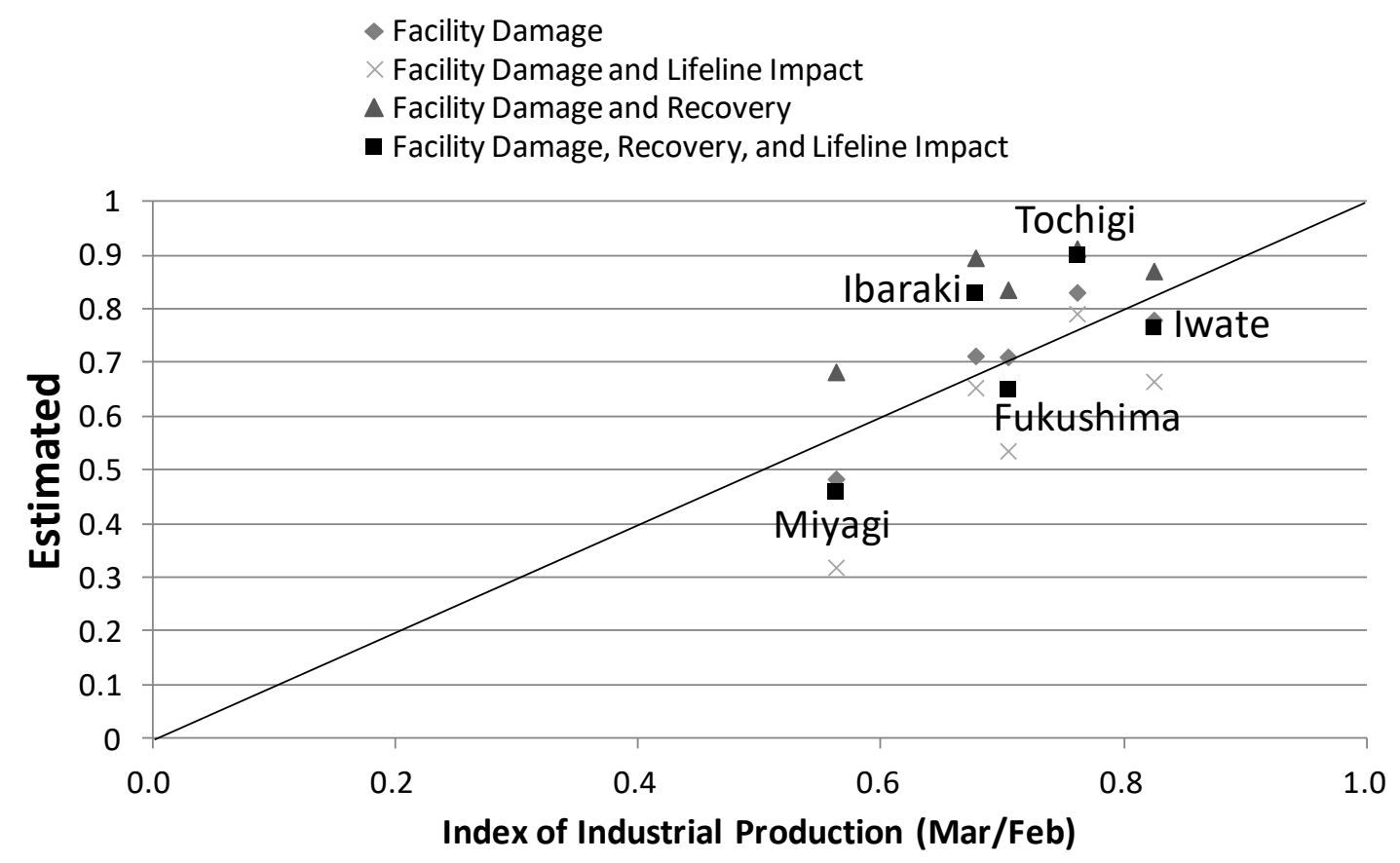

Figure 20. Comparison between estimated PCRs and IIPs in April, 2011.

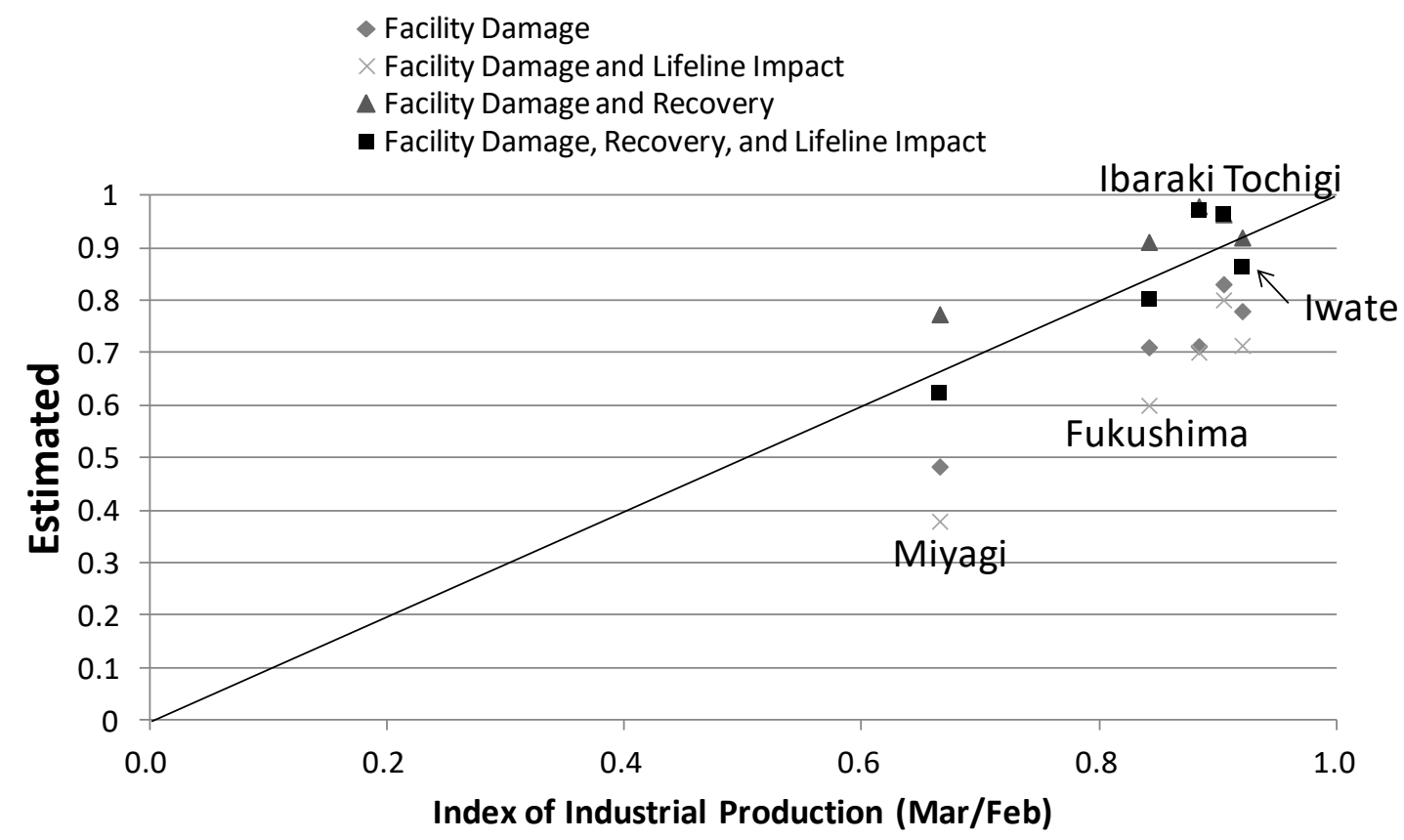

Figure 21. Comparison between estimated PCRs and IIPs in May, 2011.

\subsection{Comparison between PCRs and IIPs among different sectors}


In the previous section, the overall characteristics of estimated PCRwere discussed. Since the aggregated result for the total manufacturing sector was obtained through the value added of each sector, this result is mainly influenced by those sectors which have a large share of value added. However, damage and recovery patterns can vary in different sectors, and it is therefore necessary to investigate the applicability of the estimation model to individual industrial sectors. As such, in the following section, a comparison of various industrial sectors is conducted, based on the results of estimates for the case in which all the possible factors (facility damage and recovery and lifeline disruption impact) are considered.

Figure 22 shows the mean square errors (differences) between estimated PCRs and index of industrial production in manufacturing sectors. That is,

$$
M S E=\sum_{j=1}^{J} \sum_{k=1}^{K}\left(y_{j}^{k}-\hat{x}_{j}^{k}\right) / J K
$$

where $\boldsymbol{y}_{j}^{k}$ is IIP in region $j$, Period (Month) $k, \hat{\boldsymbol{x}}_{j}^{k}$ is an estimated PCR and $J, K$ are numbers of regions (5 prefectures) and periods ( 3 months), respectively. Figure 23 depicts the plots of original $\hat{\boldsymbol{x}}_{j}^{k}$ and $\boldsymbol{y}_{j}^{k}$ for Metal and Food sectors as references.

In Figure 22, the goodness of fit as measured using mean square error (MSE) is apparently seen to be low in the refinery \& coal and mining sectors, where the MSEs are over 0.15 . One possible reason for the relatively high MSE for the refinery \& coal sector can be explained by the nature of the damage mode in oil refineries. It is well known that some refineries were ignited and that such incidents require a long period for recovery to be completed. Similarly, in the mining sector, the types of facility and the conditions of damage incurred may differ from those in other sectors, and the lifeline resilience factor is also not as reliable since the estimate is based on only one sample.

On the other hand, more accurate goodness of fit (i.e., MSEs are small) can be observed in the apparel \& textile, metal and machinery sectors such as general machineries, electronic machineries and electronic parts. These are the sectors also frequently seen located in the midNiigata region and reflected in the estimated fragility curve. In addition, these are the industries of large value added, which have a strong effect on the estimate of PCR in the total manufacturing sector. However, among the machinery-related sectors, the transportation machinery sector appears to be uncorrelated with the relevant IIPs. This may be explained by the impact of supply 
chains on this sector. The transportation sector is composed of industries which are particularly susceptible to supply chain disruption, and industries in this sector located in the affected region may be uniquely affected by restrictions to the supply of manufacturing parts.

In other sectors, such as food, paper \& pulp and chemicals, MSEs are also small, which imply that the goodness-of-fit measures are relatively favorable. These industries are located along the coastline and would have been affected by tsunami inundation as explained in the previous section. The assumptions of zero production capacity and no recovery in tsunami-affected areas would have some validity for the duration analyzed in this study.

There still some sectors for which the results of estimates cannot be fully interpreted. In principle, however, if the types of production facilities are clearly different from the average types found in manufacturing sectors, then the goodness of fit of the capacity loss estimation model is diminished. In particular, the fragility curves used in this study are largely classified into manufacturing and non-manufacturing sectors, and analysis is limited to this classification. Those industries which are susceptible to fluctuations in demand and in the supply chain should be investigated using other approaches. These types of limitations exist within the analysis in this paper, but in several sectors at least, the proposed framework and benchmark data sets are applicable to explaining PCLR, as has been shown in the above analysis. The continuous development of a database is important in order to obtain and update statistical functions, such as the fragility curves, in more specific sectors.

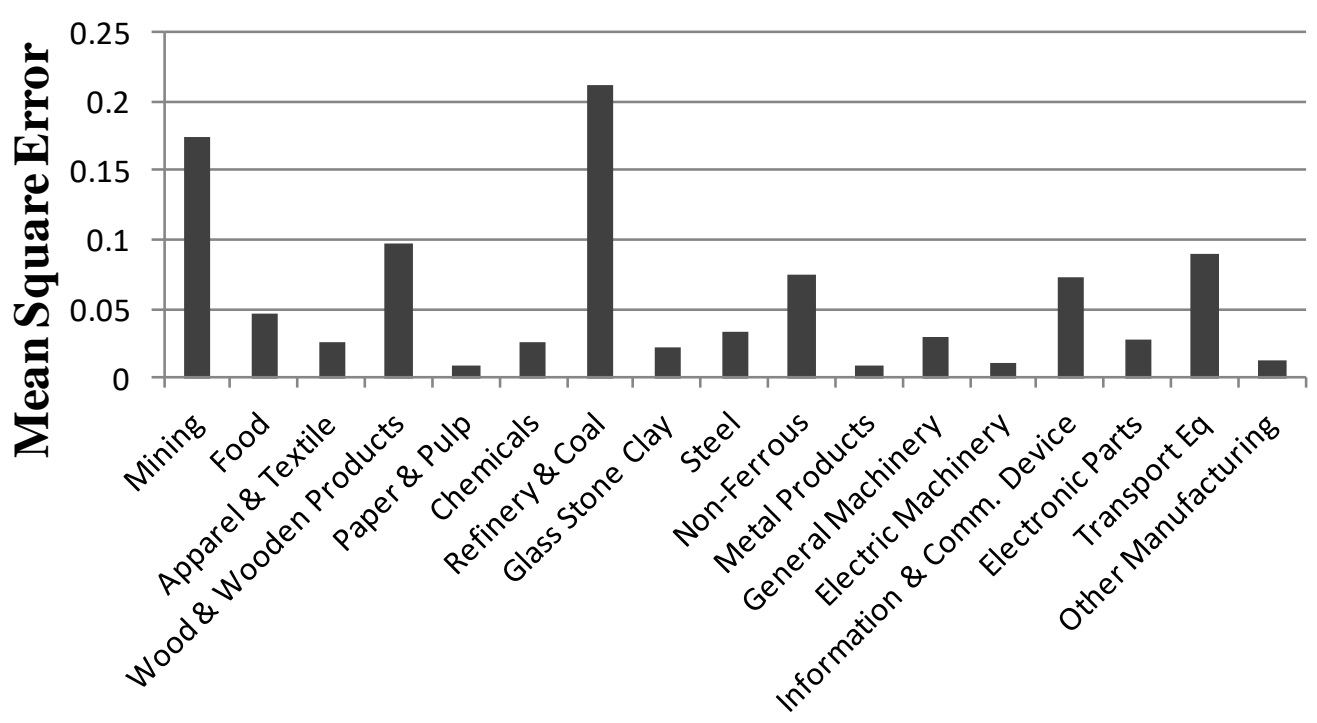


Figure 22. Mean square errors (differences) between estimated PCRsand index of industrial production in manufacturing sectors.

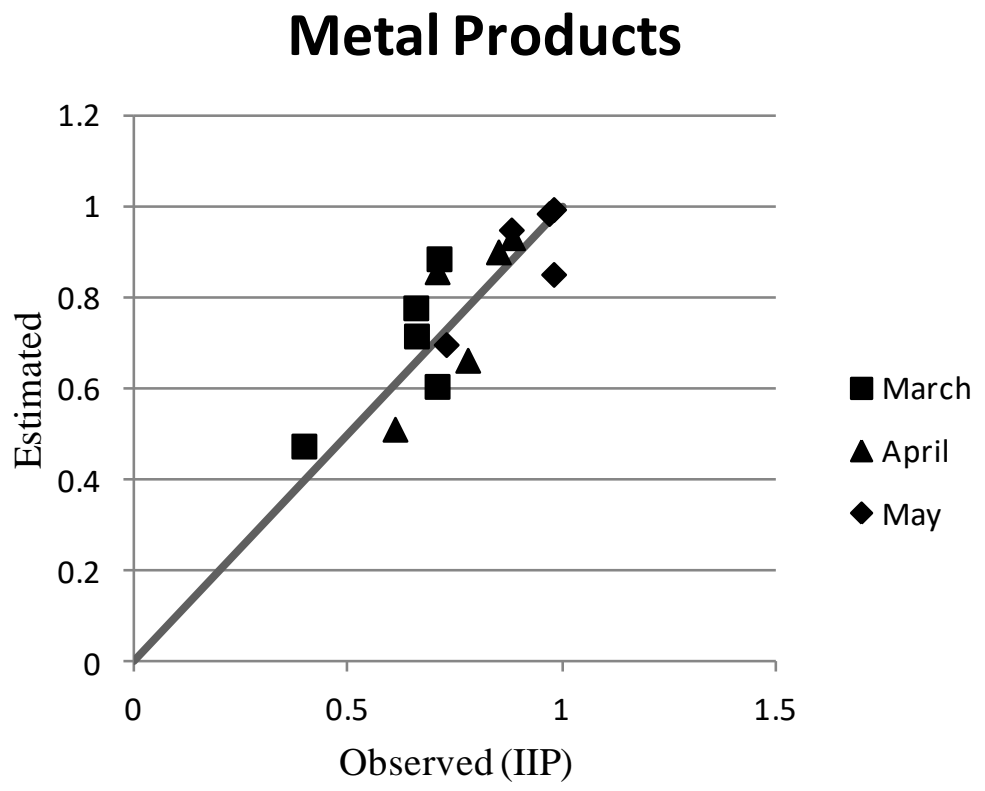

Food

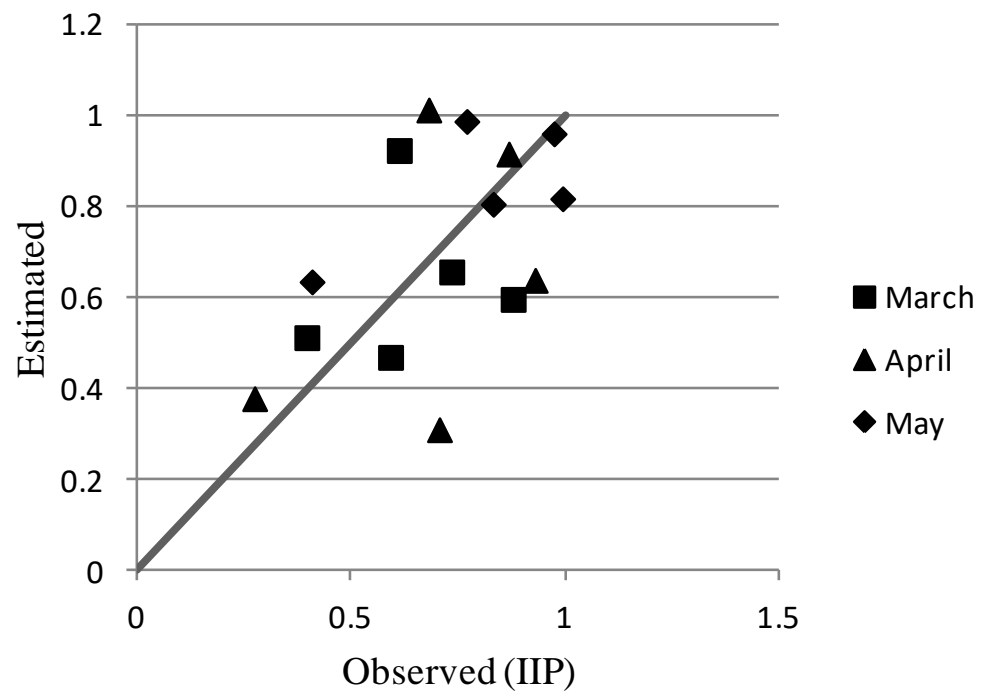

FIGURE 23 Comparison between index of industrial production and estimated PCR for metal products (upper) and food (lower) manufacturing sectors for 5 prefectures. 


\section{CONCLUSIONS}

This study investigated a methodology with which to estimate industrial production capacity loss rate (PCLR) after a disaster, particularly in the case of the Great East Japan Earthquake of March 11, 2011. PCLR is vital in estimating economic impact, but the methodology used to estimate it has not been sufficiently researched, nor has its effectiveness been validated. In particular, there exist many factors that can affect PCLR in complex ways, and the identification of the major factors and the development of a methodology to combine these factors are two of the most critical tasks faced in the accuracy estimation of PCLR. In addition, the Great East Japan Earthquake is one of the largest disasters ever recorded in the history of the world; implementing case studies to assess the economic impact of such a disaster is crucial in developing future strategies on disaster prevention for industry sectors.

Focusing on the fact that, as previous research on business impact had shown, production capacity was mainly affected by the two factors of facility damage and by lifeline disruptions, this study investigated methods for the estimation of PCLR, taking into consideration the damage and recovery status based on these two factors. In order to analyze PCLR due to facility damage, earthquake ground motions, tsunami, and nuclear accident were considered as characteristic hazards in the Great East Japan Earthquake. The functional fragility curve from the previous study was applied to estimate production capacity losses due to earthquake ground motion. As for the impact of disruption to lifeline systems, the lifeline resilience factor was applied in order to clarify the losses caused by multiple patterns of lifeline damage statuses in different regions.

The analysis showed that, in severely damaged prefectures of Fukushima, Iwate and Miyagi, there were positive correlations between estimated capacity and actual production, measured using the index of industrial production (IIP). In these prefectures, facility damage and lifeline disruption can reasonably be regarded as the major sources of impact on production capacity. Comparative analysis on different sectors made it possible to screen out applicable sectors, which included processing industries such as food, metal and machinery, and tsunami-affected sectors such as chemicals and pulp \& paper. The following three possible reasons, which can determine the forecasting capability, have been identified: the number and types of samples included in the benchmark data sets, dependency on other factors such as supply chain disruptions and demand, 
and high vulnerability from tsunami.

In this way, several implications have been obtained through this study regarding the methodology for estimating industrial PCLR, but various problems remain that must be further investigated in the future. First, in order to develop this type of empirical methodology, it is of paramount importance that data on the damage incurred and recoveries made by businesses is accumulated. The status of disaster prevention in business has gradually advanced and as such it is necessary to continuously update benchmark data used to estimate vulnerability and resilience. It is also important to investigate the facility recovery model, particularly from the aspects of damage scale and sector type. Furthermore, the assessment of the economic impact of the Great East Japan Earthquake should be conducted through multiple types of economic models. One approach to incorporate the estimated PCLRs into a regional economic model such as CGE is to estimate the consistent parameters of production function with the capacity data estimated in this research. Functional form should be carefully tested, considering the substitution among inputs, such as labor and capital.

Finally, this research focused on only the specific hazards observed in the Great East Japan Earthquake, but the analytical framework can be expanded to the case of other hazards such as floods and volcanic eruptions. For this purpose, it would be necessary to locally customize the framework and to accumulate data sets for PCLR estimation, as described in this work.

\section{ACKNOWLEDGEMENTS}

We are grateful to editors and anonymous reviewers who made valuable comments, significantly improving the quality of the paper. We also acknowledge that the research was carried out with the partial supports of JSPS KAKENHI Grant Number 24710185 and the Program for Risk Information on Climate Change funded by the MEXT-Japan

\section{REFERENCES}

Chen, K. (1996) Kobe's Industrial Damage from the Great Hanshin Earthquake: Estimation Using Grid Statistics, The Kokumin-keizai Zassi, 174, 4, 89-96 (In Japanese).

Earth Environment Engineering Group (University of Tokyo) (2012) Reaction Project for the 
2011 Off the Pacific Coast of Tohoku Earthquake", Accessed 7 January 2012 from: http://stlab.iis.u-tokyo.ac.jp/eq_data/\#ishinomaki (In Japanese).

Hallegatte, S. and M. Ghil (2008) Natural Disasters Impacting a Macroeconomic Model with Endogenous Dynamics. Ecological Economics, 68, 582-592.

Japan Gas Association (2011) Information on City Gas Outages (press release reports 1 to 63)", Accessed 4/1/12 from http://www.gas.or.jp/tohoku/press/ (In Japanese).

Kajitani, Y., Chang, S. and H. Tatano (2013a) Economic Impacts of the 2011 Tohoku-oki Earthquake and Tsunami. Earthquake Spectra, 29, S1, 457-478.

Kajitani, Y., Tatano, H. and Y. Yoshimura (2013b) Estimation of Production Capacity Losses in Industrial Sectors Due to a Large-scale Disaster: A Case of the Great East Japan Earthquake. Shizensaigaikagaku, 31, 4, 283-304 (In Japanese).

Kajitani, Y. and H. Tatano (2009) Estimation of Lifeline Resilience Factors Based on Surveys of Japanese Industries. Earthquake Spectra, 25, 4, 755-776.

Mackenzie, C.A., Santos, J.R. and K. Baker (2012) Measuring Changes in International Production from a Disruption: Case Study of the Japanese Earthquake and Tsunami. International Journal of Production Economics, 138, 293-302.

Ministry of Economy, Trade and Industry (2012) About Past Directions on Evacuation. Accessed 19 July 2012 from: http://www.meti.go.jp/earthquake/nuclear/hinan_history.html. (In Japanese)

Ministry of Health, Labor and Welfare (2011) Damage and Response Status of Water Supply System (Reports 11 to 108). Accessed from 14 March 2011 to 4 January 2012 from http://www.mhlw.go.jp/jishin/ joukyoutaiou.html. (In Japanese) 
Ministry of International Affairs and Communications (2013) 2009 Economic Census for Business Frame. Accessed 9 January 2013 from http://www.stat.go.jp/english/data/e-census/ index.htm, (Data Provider: Statistical Information Institute for Consulting and Analysis).

Nakano, K. (2011) Economic Impact Assessment of a Natural Disaster to Industrial Sectors. PhD Dissertation, Kyoto University, 2011.

Nakano, K., Kajitani, Y., Tagashira, N., Hitomi, K. and , H. Tatano (2012) Survey for Economic Impact and Business Recovery of the Great East Japan Earthquake. CRIEPI Research Report, Y11022, 50p (In Japanese).

Nikkei, Inc. (2011) Prolonged Production Recession, Nihon Keizai Shimbun, 15 March 2011. (In Japanese)

Rose, A. (2004) Economic Principles, Issues, and Research Priorities. In: Y. Okuyama and S. E. Chang (eds). Modeling Spatial and Economic Impacts of Disasters. New York, Springer, 1336.

Shinozuka, M. (2000) Statistical Analysis of Fragility Curves. Journal of Engineering Mechanics, Vol.126, No.12, 1224-1231.

Suetomi, I. and Y. Fukushima (2011) Estimation of Ground Motion Distributions in the Great East Japan Earthquake in 2011. Proceedings of 66th Annual Conference of Japan Society of Civil Engineering, CD-ROM (2 pages) (In Japanese) .

Tohoku Electric Power Company (2011) Power Outage Due to the Great East Japan Earthquake. Accessed 19 July 2012 from: http://www.tohoku-epco.co.jp/emergency/9/index.html (In Japanese). 
Tokyo Electric Power Company (2011) Press Releases in 2011, Accessed 19 July 2012 from: http://www.tepco.co.jp/cc/press/index1112-j.html (In Japanese).

United Nations United Nations Department of Humanitarian Affairs (UNDHA) (1992) Internationally Agreed Glossary of Basic Terms Related to Disaster Management. Accessed 13 September 2013 from http://reliefweb.int/report/world/internationally-agreed-glossary -basic-terms-related-disaster-management.

Geospatial Information Authority of Japan (2011) Estimation of Tsunami Inundated Area. Accessed 4 January 2012 from http://www.gsi.go.jp/kikaku/kikaku60003.html (In Japanese). 